\title{
COLLATIO DOTIS
}

JESÚS DAZA MARTÍNEZ

Catedrático de Derecho Romano

\section{ORIENTACIONES GENERALES}

Además de la collatio bonorum, en el Derecho romano clásico existía otra forma de collatio, la collatio dotis que presentaba algunos rasgos particulares ${ }^{1}$.

Fundamentalmente, la collatio dotis consistía en esto: las hijas del difunto que hubieran contraído matrimonio provistas de dote estaban obligadas a conferir ésta a sus coherederos, como conditio sine qua non para poder participar en el patrimonio del padre difunto.

El fundamento de la collatio dotis no es el mismo que el de la collatio bonorum, sino que es sólo análogo a él, tal como se evidencia en un pasaje de Ulpiano que se conserva en el Digesto.

En síntesis, se pensaba que no era justo admitir gratuitamente a la sucesión mortis causa del pater a la hija, cuando ésta había adquirido la dote por haber contraído matrimonio. La razón de esto consistía en mantener la igualdad de trato de todos los consucesores, lo cual hizo que se obligara a la hija a conferir la dote a sus hermanos.

Ahora bien, la cuestión no es tan clara como aparece a primera vista, ya que el instituto de la collatio dotis no aparece en el Derecho clásico con contornos precisos, según advertía ya ALBERTARIO en sus «Studi di Diritto Romano»².

Entre los intentos de clarificación de las cuestiones históricas y dogmáticas que están aquí en juego, hay que hacer referencia especial al estudio publicado por el Profesor GUARINO en el año 1947, en el que expone las opiniones comunes de la doctrina romanística y ofrece al mismo tiempo una síntesis original nueva cuyas claves expondremos posteriormente ${ }^{3}$.

En la doctrina romanística se pensaba entonces que era indiscutible que la collatio dotis había sido introducida por el Edicto pretorio, apoyándose fundamentalmente en la reconstrucción del Edictum hecha por Lenel ${ }^{4}$.

1 D. 37, 6,1 pr Cf. A. GUARINO, Collatio dotis, B.I.D.R., 59-50, 1948, p. 260.

2 ALBERTARIO, Studii di Diritto Romano, Vol. I, Milán, 1933, p. 289.

3 GUARINO, Collatio dotis, cit., p. 259 ss. Con posterioridad y criticando algunos puntos de la doctrina de Guarino, escribió SLECHTER, La collatio dotis, R.H.D.F.ET., 1954, p. 172 y ss.

4 LENEL, Das Edictum Perpetuum, Leipzig, 1927. 
También había coincidencia en señalar que el sujeto pasivo de la collatio dotis era únicamente la sua heres, es decir, aquélla que en el momento de la muerte del padre estaba bajo su patria potestas. Sin embargo, debe tenerse en cuenta la posición de LAURIA, según el cual no sólo estaba obligada a conferir la dote la sua heres sino también la filia emancipada, al menos después de un rescripto de ANTONINO PIO que él analiza e interpreta en este sentido ${ }^{5}$.

La doctrina común sostenía que los sujetos activos de la collatio dotis eran sólo los sui heredes. Únicamente GORDIANO habría admitido a gozar de la colación, limitadamente a la dos profectitia, también a los hijos emancipados.

A esta doctrina común se oponía ALBERTARIO, según el cual la obligación de la collatio dotis en favor de los emancipados fue una innovación postclásica, que se debió una interpolación del rescripto de GORDIANO ${ }^{6}$.

Hay acuerdo también en señalar que ANTONINO PIO introdujo un cambio radical en la doctrina de la collatio dotis. En efecto, un rescripto de este emperador extendió esta collatio también a la hipótesis de que la sua heres sucediera como heredera civil al padre sin ejercitar el ius abstinendi.

A propósito del objeto de la collatio, nadie duda que en realidad la filia no confería los bienes dotales, ya que éstos no formaban parte de su patrimonio; pero estos bienes pasarían también a formarlo si el matrimonio se disolviera por divorcio o por la muerte del marido. Así pues, la mujer prometía la colación de la dote, si y en cuanto le fuese restituida.

Las discusiones surgen cuando se trata de determinar la extensión de los bienes dotales que deberían conferirse. Generalmente se admitía que debía conferirse tanto la dos profectitia como la dos adventitia. Pero ALBERTARIO sostenía la interpolación de los textos que hablaban de conferir la dos adventitia y que, según él, sólo habría tenido lugar en el derecho postclásico.

También había acuerdo en la doctrina romanística a propósito del modo de la colación, que se consideraba idéntico al de la collatio bonorum. Sólo había una diferencia, a saber, que si concurrían varias filiae dotadas, la collatio debía tener lugar no sólo en favor de los otros sui sino también recíprocamente?

Por último, se estimaba comúnmente que la stipulatio collationis estaba regulada según principios análogos a los que estaban vigentes en materia de collatio bonorum $^{8}$. Sin embargo, GUARINO ha intentado demostrar que la regulación clásica de la stipulatio collationis fue muy distinta de lo que suele creerse ordinariamente. De acuerdo con su planteamiento, el coheredero prometía la colación ante bonorum possessionem datam, precisamente para poder obtener la datio bonorum possessionis que, de otro modo, nunca hubiera concedido el pretor ${ }^{9}$.

5 LAURIA. La Dote Romana, en Atti Soc. Reale di Napoli, 58, 1938, 79.

6 ALBERTARIO. o. cit., p. 288 ss.

7 GUARINO, art. cit., p. 261.

8 PEROZZI, Istituzioni di diritto romano, Milán, 1925, p. 641.

9 GUARINO, art. cit., pp. 262-263. 
Teniendo en cuenta estas opiniones comunes de la doctrina romanística sobre la collatio dotis, con los matices que hemos apuntado en determinados puntos concretos, vamos a exponer ahora sistemáticamente las cuestiones fundamentales relativas a los orígenes de la collatio dotis, a los sujetos activos y pasivos, a la posibilidad de renunciar a ella, a su objeto y a las medidas procesales correspondientes.

\section{ORÍGENES}

\subsection{Doctrina común}

Los principales textos que se refieren a la collatio dotis proceden del libro XL de los Comentarios al Edicto de ULPIANO:

"Quamquam ita demum ad collationem dotis Praetor cogat filiam, si petat bonorum possessionem, attamen et si non petat, conferre debebit, si modo se bonis paternis misceat; et hoc Divus Pius Ulpio Adriano rescripsit, etiam eam, quae non petierit bonorum possessionem, ad collationem dotis per arbitrum familiae erciscundae posse compelli» (D.37,7,1,pr)

«...Filiam, quae ab intestato patri eres fit, conferre quidem dotem oportet...» $(D .37,1,8)$

Los autores antiguos ${ }^{10}$ consideraron que la collatio dotis, en el sentido preciso del término, es decir, la collatio de la hija in potestate, surge con ANTONINO PIO. Esta teoría fue rechazada por FEIN; que en su obra "Das Recht der Collation", aparecida en 1.842, contiene un examen minucioso de la collatio dotis. Partiendo de la autenticidad del texto de ULPIANO (D.37,7,1,pr.), FEIN deduce el origen pretorio de la collatio dotis. El Edicto del Pretor concierne, según él, a la hija in potestate que pide la bonorum possessio. El emperador ANTONINO PIO extendió esta medida igualmente a la sucesión civil. La doctrina de FEIN fue sostenida por LENEL, a pesar de las objeciones formuladas por BESELER, concernientes a la autenticidad del texto de ULPIANO. Posteriormente LEIST y otros muchos autores defendieron la misma tesis ${ }^{11}$.

10 FEIN. Das Recht der Collation, Heidelberg, 1842.

11 LEIST. Commentario alle Pandette, L. XXVIII-XVIII, p. 535. Partidarios del origen pretorio del instituto son la mayoría de los romanistas: BIONDO-BIONDI, Diritto ereditario romano, part. gen., Milán, 1954, afirma que «Il pretore ha introdotto anche la collatio dotis, cha ha lo stesso fondamento de la precedente». SCHULZ, Derecho romano clásico, Barcelona, 1960, p. 220; SZLECHTER, art. cit. p. 172 y ss; VOCI, Diritto ereditario romano, I, Milán, 1967: «Anche la collatio dotis é un istituto de origine pretoria» p. 766. FUENTESECA, Derecho Privado Romano, Madrid, 1976: «se trata de una creación pretoria ...» (p. 572); MARRONE, Istituzioni di Diritto Romano, Palermo, 1990: «anche la Collatio dotis e di origine pretoria», (p. 829), etc. 
Ésta, que, en los comienzos de siglo nadie ponía en duda, ha sido revisada por un sector de la doctrina. A partir de esta nueva hipótesis las corrientes están divididas y, aún hoy, se sigue discutiendo.

Ambas posiciones doctrinales parten del fragmento de ULPIANO que se contiene en D.37,7,1, cuya primera parte señala que el Pretor sólo obliga a la hija a la colación de la dote, si pide la posesión de los bienes.

Así mientras para unos, basados en la referencia al Pretor que aparece en el fragmento de ULPIANO al Edictum, el origen de la collatio dotis hay que buscarlo en el Edicto Pretorio; para otros, la redacción del texto es desafortunada, técnicamente no coincide con los principios clásicos de la collatio dotis y está interpolado.

\subsection{Teoría de Guarino}

Modernamente GUARINO ha manifestado una opinión totalmente diferente de la de FEIN en lo que concierne al origen de la collatio dotis ${ }^{12}$, MOZZILLO, entre otros, que siguen esta teoría, ha escrito que «l'obbligo delle collationi estraneo all'Editto e introdotto e disciplinato nell'ambiente della giurisprudenza del II Secolo» ${ }^{13}$.

GUARINO sostiene que la collatio dotis no fue introducida ni disciplinada por el Edicto Pretorio, sino que fue creada, con toda probabilidad, por la jurisprudencia clásica, sobre la base de la interpretación de la collatio bonorum, y que la fecha de su creación hay que situarla en el siglo II d.C.

Los principales argumentos que emplea el autor, en favor de su teoría, son los siguientes:

1.-El primer periodo $D .37,7,1$ pr. es claramente espúreo. Ya BESELER, al que se opuso LENEL, sostuvo que la naturaleza del texto es la de una paráfrasis postclásica. Pueden considerarse como indicios de alteración los siguientes: «Quamquam» está construido con subjuntivo («cogat») y no con indicativo, como sería lógico. «Quamquam ... Praetor cogat filiam, ... attamen (¿filia?) conferre debebit» es un evidente anacoluto. «Debebit» está en lugar de «debet»y «filia» es

12 GUARINO. Le collazioni ereditarie, Nápoles, 1944: Noi riteniamo, insomma, che la collatio dotis «vada concepita, per diritto classico, come un istituto di formazione giurisprudenziale, il quale ebbe due campi di applicazione distinti e separati: l'uno nella bonorum possessio contra tabulas ed unde liberi, l'altro nella hereditas civile».

13 MOZILLO, v. Colattio, NN. D. I., III, p. 145. 
genérico: se comprende que se trata de la filia in potestate solamente por la segunda parte del período ${ }^{14}$.

2.- En el título D. 37,7 (de dotis collatione), a diferencia del título D. 37,6 (de collatione bonorum), encontramos, entre los pasajes que se refieren a la collatio dotis, un sólo fragmento del comentario edictal de ULPIANO. Pasajes ad edictum no encontramos en D. 37,7, a excepción del que se contiene en el fr. 1, y que es un breve pasaje del comentario ad Edictum Provinciale de GAYO (fr. 2) que todavía se refiere a la collatio bonorum. (15) Prevalece, pues, en el Título $D$. 37,7 (de dotis collatione) material extraído de obras casuísticas, lo cual induce a sospechar que la collatio dotis no es un instituto pretorio, sino una creación jurisprudencial.

3.- Una simple lectura de $D \cdot 37,7,1$ demuestra claramente que en él no sólo se habla de la sua heres, sino también, y sobre todo, de la emancipata.

Ya que como dice D. 37,7,1,1:

«Si in stipulatum deducta sit dos, si quidem ipsa mulier stipulata sit vel ipsi negotium gestum, aeque conferre cogetur...».

La mujer ha hecho una stipulatio (para la restitución de la dote) y está igualmente obligada a la colación. Evidentemente, aquí, la mujer no es una alieni iuris, sino una sui iuris, es decir una emancipata ${ }^{16}$.

4.- - La collatio dotis no pudo haber sido creada más que después de la actio rei uxoriae, que es bastante tardía. No se puede pensar, pues, que el Edicto Pretorio haya introducido la collatio dotis, es decir, un instituto que, si no presupone que la dote es propiedad de la mujer, presupone, al menos, que volverá, en la mayor parte de los casos a la mujer, después de la ruptura del matrimonio ${ }^{17}$.

El punto de partida es, para GUARINO, la collatio bonorum. La jurisprudencia ha extendido la noción de los bona sua de la collatio bonorum a la dote

14 GUARINO. Le collationi ..., art. cit. afirma a propósito de D. $37,7,1$ «Gli indizi di forma non mancano. Quamquam é costruito col coguintivo cogat anziché con l'indicativo» y añade «In conclusione, noi ci troviamo a dover risolvere questo problema. ULPIANO ha probabilimente parlato di una filia (che specie di filia?) tenuta conferire la dos per disposizione dell'editto pretorio; se editto pretorio; se ed in quanto chiedesse ámmisione alla bonorum possessio; forse egli ha anche aggiunto che la filia (quale filia?, la stessa della prima ipotesi?) e tenuta al conferimento anche in altri casi ed in particolare anche quando succeda al pater iure civili». Por ello dice que «tutavía (e qui il secondo corno del dilemma) un commentatore postclásico ha parafrasato queste dichiarazioni di ULPIANO per renderle piú concise, e le parafrasi postclassica ha sostituito, nel caso delle transcrizioni, l'originario dettato classico. Il dubbio che la parafrasi postclássica non rifleta con tuta chiareza, principalmente a causa della sua studiata concisione, il primitivo insegnamento di ULPIANO mi sembra incoercible». (p. 140).

15 GUARINO. Collatio Dotis, Art. cit. p. 266.

16 GUARINO. Art. cit. p. 266 y ss.

17 GUARINO. Art. cit. p. 267. 
(primera etapa). Así, pues, en primer lugar, la hija emancipada y dotada fue obligada a la colación de la dote. Posteriormente, la jurisprudencia extendió esta obligación a la filia in potestate que pedía la bonorum possessio (segunda etapa). Finalmente, gracias a un rescripto de ANTONINO PIO, se sometió a esta obligación a la hija sua heres llamada a la sucesión civil.

GUARINO concluye «in mancanza di prove piú degne del parafrastico primo periodo di D.37,7,1, é legittimo, e sopra tutto prudente, ritenere che la collatio dotis non sia stata introdotta dal praetor urbanus, ma che essa si sia affermata progressivamente attraverso l'elaborazione giurisprudenziale del II s., d.C. ${ }^{18}$.

\subsection{Crítica de la Doctrina de Guarino}

La doctrina de GUARINO, a pesar de su rigor y de su coordinación lógica, suscita algunas dificultades:

1.- No creemos que las interpolaciones formales indicadas por GUARINO, sirvan para desechar el texto. La proposición "Quamquam ita demum ad collationem dotis praetor cogat filiam si petat bonorum possessionem» no tiene el carácter que señala el autor, sino que designa la categoría de hijas que el Pretor obliga a la colación de la dote, y que no engloba únicamente a las hijas in potestate.

2.- No nos parece un argumento suficiente el hecho de que sólo sea un pasaje de ULPIANO el que haga referencia a la collatio dotis, ya que GAYO, D. 37,7,2 como el mismo GUARINO admite, hace igualmente alusión al Edicto del Pretor.

3.- El texto de ULPIANO no parece indicar únicamente la hija in potestate, por lo tanto el argumento de GUARINO, sobre el particular, no nos convence.

4.- En cuanto a la fecha de la aparición de la actio rei uxoriae, que condiciona el nacimiento de la collatio dotis, creemos que es mucho anterior que la que señala GUARINO. Se puede dudar de la naturaleza jurídica de la acción mencionada por POLYBIO $(18,18,6 ; 32,8,4)$, por DIODORO $(31,26)$ por PLUTARCO (Vita 4,5), por JAVOLENO (D. 24,3,66 pr): $i$ en los casos citados se trata de la cautio rei uxoriae o de la actio rei uxoriae?

Se puede discutir sobre la interpolación del pasaje de PAULO (D. 24,3,44 pr.), pero CICERON, Top. 17,66, nos indica expresamente: «in arbitrio rei uxoriae, in quo est (quid) aequius et melius erit».

LABEON, por su parte, en D. 23,3,79 pr. nos informa que la actio rei uxoriae era conocida por SERVIO SULPICIO, muerto en el año 43 a.C.

Pensamos con SZLECHTER que «l'actio rei uxoriae est certaine dès la fin du II siecle av. J.C. au plus tard au début, et il n'y a donc aucune impossibilité à placer l'origine de la collatio dotis aut debut du Principat».

18 GUARINO. Art. cit. p. 145. 
La mayor parte de la doctrina no duda del origen pretorio del instituto ${ }^{19} \mathrm{e}$ incluso algún romanista, como ARANGI0-RUIZ, estima que los pretores republicanos ya tenían conocimiento de la colación de la dote ${ }^{20}$.

\subsection{Nuestra Posición}

Pensamos que no se puede dudar de la naturaleza pretoria de la collatio dotis y ello en base a los siguientes argumentos:

A) Como ya ha quedado demostrado, la hija, por derecho propio, participa en la sucesión $a b$ intestato paterna. Su concurso produjo, desde el principio, el mismo problema que ya conocemos de la collatio bonorum, esto es, la reducción de los derechos hereditarios civiles de sus hermanos. En realidad, aquí el magistrado no trata de equiparar las distintas adquisiciones de los coherederos sui y emancipados, por el perjuicio que causa la patria potestad, sino porque la hija que contrae un matrimonio se beneficia de un conjunto de bienes que sus hermanos sui iuris, y los sometidos a la potestas de un paterfamilias, no han podido disfrutar, « ... ad collationem dotis Praetor cogat filiam, .... conferre debebit, si modo se bonis paternis misceat $\rangle^{21}$.

B) Otro motivo que confirma esta tesis es que el pretor aplica las mismas reglas a este tipo de colación que las ya recogidas en el apartado del álbum para la collatio bonorum. A pesar de este paralelismo, aquel distingue perfectamente ambos institutos:

1) En la collatio bonorum, a decir de JULIANO, los sujetos activos o pasivos del procedimiento son los heredes sui y los emancipados:

«Ibidem Iulianus ait, si bonorum possessione accepta decesserit is, qui in potestate est, ad collationem bonorum cogendum emancipatum, ut tantum heredi eius conferat, quantum conferret ipsi si viveret... ${ }^{22}$.

2) En la Collatio dotis sujetos del procedimiento son la mujer, en cuanto ha sido dotada, con independencia de si es sui iuris o alieni iuris, y sus hermanos sui:

19 SZLECHTER, E. La Collatio Dotis, R.H.D.F.ET., p. 174.

20 ARANGIO-RUIZ. Istituzioni di Diritto Romano, Nápoles, 1947, p. 540 señala que «Un'altrá iniquita era giá stata evitata dai pretori repubblicani», y añade que «análogamente, alla figlia maritata che pur rimanendo in potestá del padre avesse ottenutto per sé o per la famiglia maritale il beneficio della dote, fu imposta, se voleva concorrere coi fratelli nell'ereditá, la collatio dotis».

21 D. $37,7,1$. D. $37,7,1,1$.

22 D. $37,6,1,8$. 
«Filiam, quae ab intestato patri heres fit conferre quidem dotem oportet, consequens autem est, ...» ${ }^{23}$.

3) Objeto de colación son en una: los bienes de los sui iuris y en otra: la dote. Ambas clases de patrimonio son de distinta naturaleza jurídica, tanto por el modo de constitución, cómo por la finalidad que tienen asignada por el derecho ${ }^{24}$.

4) Estas peculiaridades hacen que el fundamento sea análogo pero no idénti$\mathrm{co}^{25}$. El hecho de que la hija deba colacionar la dote entregada por su padre demuestra con claridad que el Pretor y los coherederos tenían en cuenta las entregas de bienes que aquel había hecho en vida. No puede haber la menor duda de ello, porque los mismos hermanos ven reducida su cuota hereditaria con la presencia de su hermana en el concurso sucesorio. En este sentido ULPIANO manifiesta que:

«Si sub condicione pater, vel extraneus dotem promiserit, cautione opus erit, ut tunc conferat mulier dotem, quum dotata esse coeperit $\rangle^{26}$.

C) Hay otras razones específicas para sostener el origen edictal de la collatio dotis:

1) Los comentarios al Edicto de ULPIANO en su Libro $X I X^{27}$, y $X L$ ad Edictum $^{28}$, y los de GAYO al Edicto Provincial no pueden dejar duda de ello ${ }^{29}$. El hecho de que los compiladores hayan recogido en dos títulos distintos del DIGESTO, XXXVII y XXXVIII ambos tipos de colaciones, demuestra que los institutos tienen una personalidad distinta y separada. Los comisarios de TRIBONIANO las habrían recogido en el mismo título de las Pandectas si hubiesen estado en el mismo apartado edictal.

2) Analicemos los testimonios de ULPIANO contenidos en $D .37,6,1$ y $D$. $37,7,1$ :

23 D. $37,7,1,8$.

24 Las fuentes demuestran esta distinción. Objeto Collationis: D. 37,6,1, ULPIANO, Libro XL ad Edictum, "...Participesque faciat cum his, qui sunt in potestate, bonorum paternorum, consequens esse credit». D. 37,6,1,3 «..., emancipatum accipientem contra tabulas pro quadrantem tantum bona sua collaturum Iulianus ait, quia solum quadrantem fratri abstulit». Objeto dotis, D. 37,7,1, ULPIANO, Libro XL ad Edictum "Quamquam ita demum ad collationem dotis Praetor cogat filiam». D. 37,6, 1,1, ULPIANO, Libro XL ad Edictum «Si in stipulatum deducta sit dos, si quidem ipsa mulier stipulata sit, vel ipsi negotium gestum, aeque conferre cogetur». SZLECHTER, art. cit. p. 172 señala a próposito de los jurisconsultos que «Ils distinguent expréssement, en ce qui concerne la fille émancipée et dotée, les bona sua et la dos».

25 GUARINO. Collatio Dotis, B.I.D.R., 49-50, 1947, p. 259 y ss. señala que «Il fondamento dell'istituto della collatio dotis non fu evidentemente lo stesso della collatio emancipati, ma fu soltanto un fondamento analogo a quello».

26 D. $37,7,1,7$.

27 D. $10,2,20$.

28 GAYO. III, XXV.

29 D. $37,7,2$. 
A propósito de la collatio bonorum el jurista señala que:

«Hic titulus manifestam habet aequitatem; quum enim Praetor ad bonorum possessionem contra tabulas emancipatos admittat, participesque faciat cum his, qui sunt in potestate, bonorum paternorum, consequens esse credit, ut sua quoque bona in medium conferant, qui appetant paterna $\aleph^{30}$.

El mismo autor, en relación a la Collatio Dotis, afirma que:

«Quamquam ita demum ad collationem dotis Praetor cogat filiam, si petat bonorum posessionem, attamen et si non petat, conferre debebit, si modo se bonis paternis misceat. Et hoc Divus Pius Ulpio Adriano rescripsit, etiam eam, quae non petierit bonorum possessionem, ad collationem dotis per arbitrum familiae erciscundae posse compelli» ${ }^{31}$.

Ambos textos hacen mención a la figura del Pretor. Comienza el autor señalando que si los hijos tienen la legitimación debida para participar en la sucesión $a b$ intestato, el Pretor ordena que colacionen sus bienes. La bonorum possessio no se pide ante otra persona diferente, en época clásica. Sólo él tiene competencia exclusiva en materia de posesión de bienes. Aunque el segundo fragmento ulpianeo pudiese contener interpolaciones, como sostiene algún autor ${ }^{32}$, es innegable que los presupuestos citados están acordes con los principios del derecho clásico hereditario vigentes para la colación de la dote.

Por otro lado, el mismo ULPIANO comienza con un «quamquam». El autor observa que existe una normativa imperial que completa al Edicto en materia de colaciones. Ya no es necesario que la hija sea sucesora intestada. Como heredera civil, si quiere participar en el caudal relicto y no ha ejercido el ius abstinendi, debe aportar su dote a la masa hereditaria, para su división por el juez de familia. Por este motivo, aunque la conjunción no está muy acorde con el subjuntivo "cogat», puede haber sido un defecto de estilo del amanuense que lo ha copiado, recogiendo el texto original ulpianeo ${ }^{33}$, aunque tal vez, la verdadera razón del comienzo por esta conjunción es la oposición a lo que ULPIANO manifiesta en la segunda parte del fragmento, relativo a la disposición imperial de Antonino Pío.

El primer texto prescribe que el obligado a colacionar es el emancipado. En el segundo, si el jurista no cita la clase de hija es debido, por un lado, a que a priori,

$\begin{array}{ll}30 & \text { D. } 37,6,1 . \\ 31 & \text { D. } 37,7,1 . \\ 32 & \text { Cfr. nota } 14 . \\ 33 & \text { Cfr. nota } 14 .\end{array}$


tiene derecho a la posesión de los bienes, «... Si petat bonorum possessionem» ${ }^{34}$, y por otro, lo importante es que esté dotada, «Quum dos confertur...» ${ }^{35}$.

En conclusión, la redacción de los textos es casi paralela. Nos encontramos ante dos leyes diferentes que regulan en su normativa instituciones paralelas pero no iguales.

D) Las técnicas jurídico-procesales, recogidas en el Edicto, son aplicadas, indistintamente, a ambas instituciones:

1) En primer lugar los sujetos obligados a aportar sus bienes tienen que prestar una caución estipulatoria, con promesa formal antecedente, de que llevarán a cabo la colación. ULPIANO confirma esta tesis:

«Stipulatio autem collationis tunc committitur, quum interpellatus cum aliquo spatio, quo conferre potuit, non facit, maxime, quum boni viri arbitratu collationem fieri Edicto Praetoris insertum est $\rangle^{36}$.

El mismo jurista dice a propósito de la estipulación de la dote que:

«Si in stipulatum deducta sit dos, si quidem ipsa mulier stipulata sit, vel ipsi negotium gestum, aeque conferre cogetur; si vero alii quaesita est stipulatio, dicendum est, cessare collationem; et si tantum promissa sit dos, collatio eius fiet $»^{37}$.

Al disolverse el matrimonio, la dote debe restituirse a la mujer, siempre que ésta sea independiente. Si está bajo la potestad de su padre y la dote procedió de éste, la dote pertenece al padre y a la hija a la vez, aunque el padre no puede reclamar la dote sin el consentimiento de su hija, ni él directamente ni por medio de su procurador, y así debe hacerse también la promesa ${ }^{38}$. En el intervalo de tiempo que tarda en recuperarla no se puede dejar sin garantías jurídicas a los coherederos. Este es el motivo por el que tiene que prestar una garantía caucional, que asegure el cumplimiento de la obligación. Si ULPIANO indica en el primer texto, que esta técnica procesal se recoge en el álbum honorario para los emancipados, es lógico suponer que el procedimiento estaba prescrito de modo idéntico

\footnotetext{
34 D. $37,7,1$.

35 D. $37,7,1,5$.

36 D. $37,6,5,1$.

37 D. $37,7,1$.

38 D. $24,3,2$, ULPIANO, Libro XXV ad Sabinum, «Soluto matrimonio solvi mulieri dos debet». D. 24,3,2,1, ULPIANO, Libro XXV ad Sabinum «Quodsi in patris potestate est, et dos ab eo profecta sit, ipsius et filiae dos est. Denique pater non aliter, quam ex voluntate filia petere dotem nec per se, nec per procuratorem potest». D. 24,3,3, PAULO, Libro VII ad Sabinum dice «Non solutum autem in exigenda, sed etiam in solvenda dote, quae communis est patris et filiae, utriusque voluntas exquiritur».
} 
para las dotadas. Es cierto que, en el segundo fragmento, no la menciona expresamente, pero el autor nos enseña que el procedimiento es el mismo para ambas. Por este motivo presumimos que no se puede discutir su origen honorario.

2) Cuando los coherederos solicitan la posesión de los bienes y prestan la garantía caucional, se someten a la jurisdicción de un árbitro, encargado de hacer cumplir la colación. PAULO se plantea la cuestión acerca de lo que pereció sin culpa del hijo emancipado después de morir su padre y afirma:

«De illis, quae sine culpa filii emancipati post mortem patris perierunt, quaeritur, ad cuius detrimentum ea pertinere debeant. Et plerique putant, ea, quae sine dolo et culpa perierint, ad collationis onus non pertinere; et hoc ex illis verbis intelligendum est, quibus Praetor viri boni arbitratu iubet conferri bona; vir autem bonus non sit arbitraturus, conferendum id, quod nec habet, nec dolo, nec culpa desiit habere ${ }^{39}{ }$.

PAPINIANO sobre la colación de la dote dice que:

«Filia, quae soluto matrimonio dotem conferre debuit, moram collationi fecit; viri boni arbitratu cogetur usuras quoque dotis conferre, quum emancipatus frater enim fructus conferat, et filia partis suae fructus percipiat ${ }^{40}$.

El fragmento recoge una respuesta sobre un caso práctico que le ha sido planteado por algún particular, labor característica de la jurisprudencia clásica. El autor manifiesta que el emancipado colaciona sus frutos, sometido a la iurisdictio de un árbitro. La hija también lo lleva a cabo, porque el Edicto, que él debe conocer perfectamente, así lo prescribe. Esto no significa que el jurista, con su interpretación, haya innovado el mismo sistema para la hija, sino que para la solución del problema ha utilizado las normas pretorias «cristalizadas». Constituye una prueba más de que el Pretor distinguía ambas colaciones perfectamente, si no ¿por qué recurrir al apoyo de la collatio bonorum? Si son institutos idénticos ¿por qué el autor habría distinguido dónde no se debe distinguir?

3) Otra razón, en favor del origen pretorio de la collatio dotis, se deduce claramente del modo de hallar el montante patrimonial neto al que están sujetos los obligados a aportar sus bienes. Los emancipados tienen en su patrimonio lo que queda después de deducir las deudas. Esto no es igual en la collatio dotis.

PAULO señala la regla para los sucesores sui iuris:

39 D. $37,6,2,2$.

40 D. $37,7,5,1$. 
«Illud autem intelligendum est, filium in bonis habere, quod deducto aere alieno superest. Sed si sub conditione debeat, non statim id deducere debebit, sed id quoque conferre; contra autem caveri ei oportebit ab eo, qui in potestate est, ut existente conditione defendatur pro ea parte, quam contulit $»^{41}$.

ULPIANO hace lo propio con la colación de la dote:

«Quum dos confertur, impensarum necessariarum fit detractio, ceterarum non ${ }^{42}$.

El texto ordena que la mujer deduzca los gastos necesarios. El autor dice que, en esta clase de colación no se restan todos los débitos como en la primera. Por eso acaba el fragmento con la expresión, «...ceterarum non». A esta idea se puede objetar que en el ejercicio de la administración de la dos, que lleva a cabo un cónyuge, existen además otras clases de gastos, y así el autor, lo que ha hecho, es delimitar los que están incluidos en el pasivo. Si esto es cierto, no se puede negar que el procedimiento aquí es similar, pero no igual. El sistema se recoge dentro de los comentarios al Edicto.

4) No aceptamos la idea, que sostiene GUARINO, de que el derecho a la restitución de la dote, de la que es titular la mujer, en el momento en que se disuelve su matrimonio por divorcio o muerte de su marido, sea un principio que se desarrolla en el S. II d.C. Como ya afirmamos anteriormente, el nacimiento de la actio rei uxoriae es anterior.

CICERON, jurista que vivió a finales de la República, ya la conoce. Sobre ella nos dice que:

«.... in arbitrio rei uxoriae in quo est quid aequis melius erit ${ }^{43}$.

El propio AULO GELIO centra su aparición en el siglo II de la fundación de Roma, como consecuencia de un divorcio que escandalizó la ciudad:

«...Sed Marcus Cato non solum existimatis, sed multatas quoque a iudice mulieres refert non minussi vinum, in se, quam si probrum et adulterium admisissent, verba M. CATONIS adscripsi ex oratione, quae inscribitur de dote, in qua id quoque scriptum est, in adulterio uxores

$41 \quad$ D. $37,6,2,1$.

42 D. $37,7,1,5$.

43 CICERON. De Off. 3,15,61. 
deprehensas ius fuisse maritis necare: Vir, inquit quum divortium fecit, mulieri iudex pro censare est imperium videtur, habet si quid pervese» ${ }^{44}$.

JAVOLENO recogiendo la tradición jurídica anterior, señala el derecho legítimo que tiene LICINIA, mujer de uno de los hermanos GRACO, de recuperar su dote:

«In his rebus, quas praeter numeratam pecuniam doti vir habet, dolum malum et culpam eum praestare oportere, Servius ait; ea sententia Publii Mucii est, nam is in Licinia gracchi uxore statuit, quod res dotales in ea seditione, qua Gracchus occisus erat, periissent; ait, quia Gracchi culpa ea seditio facta esset, Liciniae praestari oportere ${ }^{45}$.

5) GAYO, en el Libro XIV de sus Comentarios al Edicto Provincial, confirma que la hija dada en adopción e instituida heredera debe colacionar, así como la emancipada, no sólo sus bienes, sino también la dote que puede llegar a pertenecerle. Si vive todavía el padre adoptivo, deberá colacionar éste:

«Filia in adoptionem data et heres instituta debet, sicut emancipata, non solum bona sua, sed et dotem, quae ad eam pertinere poterit, conferre; si adhuc pater adoptivus vivit, hic necesse habebit conferre ${ }^{46}$.

Es el caso de la hija dada en adopción que, en el momento del fallecimiento de su progenitor, desea participar en la herencia. El autor distingue varios casos:

a) Si la hija está bajo potestad de su padre adoptivo, éste es el que lleva la dote a colación.

b) Si la hija ha sido emancipada por su padre adoptivo, es ella la que soporta la carga de la aportación de los bienes.

El texto citado vamos a ponerlo en relación con otro de ULPIANO en el que hace referencia a la colación de un hijo adoptivo:

44 AULO GELIO. Noct. Att, 4, 3, 1-2. AULO GELIO, Noct. Att. «sed Marcus Cato non solum existimatis, sed multatas quoque a iudice mulieres refert non minus si vinum, in se, quam si probrum et adulterium admisissent, verba $M$. CATONIS adscripsi ex oratione, quae inscribitur de dote, in qua id quoque scriptum est, in adulterio uxores deprehensas ius fuisse maritis necare: Vir, inquit, quum divortium fecit, mulieri iudex pro censare est imperium videtur, habet si quid pervese».

45 D. 24,3,66 PLUTARCO. Vita, 4, 5. No hay duda que la Actio Rei Uxoriae es anterior al S. II d. C. En esta dirección BONFANTE, Corso di Diritto Romano I, cit. p. 462 y ss. dice que «Si nostri giorni una visione piú chiara non sollo delle particolaritá del rapporto dotale ma altresi del caracttere delle fonti giuridiche nel diritto romano, fece si che si inclinase piuttosto ad attribuire questa origine o alla legge o all'eddicto del pretore». SZLECHTER, art. cit. p. 174 dice que «Nous considerons q l'actio rei uxoriae est certaine dés la fin du II siécle av. J-C. an plus tard, et il n'y a donc ancune impossibilité á placer l órigine de la collatio dotis au debut du Principat». 
"Is quoque, qui in familia adoptiva est, conferre cogitur, hoc est, non ipse, sed is, qui eum habet, si maluerit contra tabulas bonorum possessionem accipere. Plane si hic adoptivus pater ante bonorum possessionem petitam emancipaverit eum non cogetur ad collationem; et ita Rescripto Divorum Fratrum expressum est.Sed ita demum adoptivus emancipatus collatione fratres privabit, si sine fraude hoc factum sit» ${ }^{47}$.

El caso mencionado, en cuya solución se aducen razones de un rescripto de MARCO AURELIO y LUCIO VERO, es semejante al planteado por GAYO, aunque existen clarísimas diferencias:

a) El caso comentado por GAYO no se refiere sólo a la collatio emancipati sino también a la «collatio dotis». Si la dote se considera un conjunto de bienes que tienen la misma naturaleza jurídica que el patrimonio de los emancipados, y la mujer tiene la plena disponibilidad sobre ellos, no habría sido necesario que el autor hubiese mencionado «...non sola bona sua, sed et dotem,...conferre» ${ }^{48}$. De este modo, significa el jurista que la hija debe entregar por un lado, los bienes que haya obtenido desde que el padre adoptivo la dio su independencia, y por otro, la dote constituida por él o por su progenitor natural. Estas aportaciones se llevan a cabo a través de una clase u otra de colación, dependiendo de la clase de bienes que deba conferir.

b) Si la hija está bajo la potestad de su padre adoptivo, «... si adhuc pater adoptivus vivit» ${ }^{49}$, el sujeto obligado a la colación es aquél. En este caso entrega la dote, pero no los bienes de su hija, porque no los tiene. Esta colación se lleva a cabo por un capítulo independiente y es por ello por lo que Gayo hace distinción de ambas categorías de bienes, porque aunque el sistema collationis sea el mismo, como creo que ya ha quedado demostrado, las vías pretorias son diferentes. Así el jurisconsulto podría haber dicho que la hija dotada bajo potestad de un paterfamilias adoptivo colaciona por el mismo capítulo del Edicto que la emancipada, pero no lo hace.

c) Los hermanos emancipados no colacionan la dote porque es un patrimonio que no les pertenece. ULPIANO dice que:

«Si emancipatus filius, qui contra tabulas bonorum possessionem accepit, filiam dotatam habeat, non debet eius conferre, quia in bonis eius non est» ${ }^{50}$.

$47 \quad$ D. $37,6,1,14$.

48 D. $37,7,2$.

49 D. $37,6,1,14$.

50 D. 37,7,1,9. D. 37,6,4, AFRICANO, Libro IV Ouaestionum señala que «Filium emancipatum dotem, quam filiae suae nomine dedit, conferre non debere, quia non sicut in matrisfamilias bonis esse dos intelligatur, ita et in patris, a quo sit profecta». 
Si el capítulo del Edicto prohibe a los hermanos de sexo masculino llevarla a colación, ¿por qué por este mismo capítulo edictal se iba a permitir a las hermanas de sexo femenino? Aunque consideremos que la dos es privativa de la mujer y que tiene expectativas legales para recuperarla, no se puede afirmar que la mujer dotada sea como si fuera emancipada, porque, en realidad, una cosa si está clara en época clásica: qué es un sujeto emancipado con los bienes que haya adquirido y qué es la hija que ha sido dotada para contraer matrimonio. ¿Por qué el magistrado recurría a la ficción de considerarla como tal? Las fuentes no dan ninguna prueba de ello, sino de todo lo contrario, esto es, distinguen entre ambas clases de bienes y de personas, tanto en los títulos de las Pandectas, como en los títulos relacionados con el ordenamiento jurídico de la dote en general.

\subsection{Conclusiones}

Por todos los argumentos anteriormente expuestos, creemos que con respecto al origen de la collatio dotis, podemos concluir:

1) No se puede dudar que el origen del instituto sea obra del Pretor, consecuencia de su labor correctora y complementaria del Ius Civile, en materia de sucesión intestada.

2) En el Edicto aparecieron dos títulos distintos y bien diferenciados, con carácter sucesivo, que contenían la normativa de ambas colaciones.

3) El Pretor diferenció claramente los dos institutos, como se pone de manifiesto por el tratamiento que da tanto a los sujetos como al objeto de ambas colaciones ${ }^{51}$.

4) El nacimiento de ambas debió ocurrir en la misma época, que yo sitúo en el s. I a.C., puesto que responden a una filosofía análoga.

La hija es beneficiaria de la posesión de los bienes. Su participación en la herencia intestada del ascendiente produce una reducción en los derechos patrimoniales de sus hermanos coherederos. Sin embargo la estructura particular de la dote, su finalidad y las personas que la constituyen, entre la que se encuentra el padre, demuestra que la ratio de los institutos es análoga pero no idéntica, porque con la colación de los emancipados se corrigen las distorsiones patrimoniales generadas por la patria potestad, pero con la colación de la dote hay un anticipo patrimonial en vida del padre a la hija ... «AD SUSTINERE ONERA MATRIMONII $»^{52}$, que es el que genera ventajas en los derechos sucesorios de aquella $^{53}$.

51 SZLECHTER. Art. cit. p. 177.

52 BONFANTE, Corso di Diritto Romano, I, Diritto di Famiglia, Milán, 1963, p. 338.

53 Ver nota 40 . La prevalencia de las relaciones cognaticias es atestiguada por las fuentes que tratan de la nueva sucesión hereditaria pretoria. GAYO, III, 25; III, 34. VOCI, Studi di Diritto Romano, Il Diritto Ereditario Romano dalle origini alle Severi, p. 482, y ss. afirma que «Nell'ambito dell'hereditas nuovi istituti si aggiungono agli antichi, per es. in materia di successione ab intestato: propio qui si 
5) La jurisprudencia clásica no es la que da vida al instituto. Su intervención es decisiva en los consejos imperiales. Esta labor se manifiesta, sobre todo, a partir de la intervención de los Emperadores en materia de dotis collatione. Su influencia se plasma en los diferentes rescriptos que aluden directamente al instituto. Según el estado de las fuentes, podemos señalar que la legislación, que completa las normas honorarias vigentes sobre la materia, nace a partir del mandato de ANTONINO PIO. Desde entonces, su actividad, sobre el ordenamiento establecido, es ininterrumpida. El emperador Gordiano en el año 239 d.C. señala que ha recibido el apoyo de sus jurisconsultos:

$$
\text { «... Post varias prudentium opiniones conferri placuit» }{ }^{54} \text {. }
$$

El Código Justineaneo recoge muchas constituciones que demuestran la intervención casi constante de los Emperadores en materia de colación.

\section{CONSTITUCIÓN DE LA DOTE Y COLACIÓN}

\subsection{Introducción}

Previamente estudiaremos el siguiente problema de fondo:

Debemos preguntarnos si cuando los romanos entregan la dote a sus hijas lo hacen con ánimo de donación o no. Si la respuesta es positiva, significa, que la recepción de la dote profecticia por la hija, es un anticipo de los bienes hereditarios en vida. Ello puede ayudar a entender mejor la ratio de la collatio dotis en época clásica y su evolución posterior en la etapa postclásica, que es cuando nace la colación de los descendientes.

FESTO señala que:

«... Dotem manifestum est a graeco esse: nam didonai dicitur apud eos dare $\gg^{55}$.

viene a parlare di ius civile novum» y añade posteriormente «L'ammissione della bonorum possessio incondizionata é di grandissima importanza, per due motivi: Il primo é che cosí viene introdotta la bonorum possessio corretoria, che prevale sul diritto civile. Il secondo é che lo schema generale della successione pretoria non solo diventa completo, ma anche tassativo: ciascuno consegue 1 éreditá solo secondo 1 órdine dell editto, e ció importa la prevalenza del regimen pretorio su quello civile».

54 C. $V I, 20,4$.

55 VARRO. De L.L., $10,36,48$. 
Algunos autores como LAURIA ${ }^{56}$ y BONFANTE ${ }^{57}$ sostienen que ya desde la etapa primitiva-arcaica el paterfamilias dona al marido de la hija casada cum manu o a su paterfamilias, unos bienes.

En épocas más evolucionadas la constitución de la dote, se puede llevar a cabo por los más diversos medios, y a través de negocios jurídicos diferentes. Uno de ellos fue la donación, como liberalidad de una persona que la lleva a cabo con respecto a otra que la acepta.

El marido se hacía propietario de los bienes dotales; pero ya en el derecho clásico existieron limitaciones legales a su capacidad de disposición. Una Lex Julia de fundo dotali prohibió al marido enajenar sin consentimiento de la esposa los fundos dotales itálicos, e hipotecarlos aún contando con su conformidad ${ }^{58}$.

Examinemos algunos textos de los juristas clásicos que tratan de la constitución dotal a través de la dotis datio. ULPIANO sobre la sponsio llevada a cabo entre un particular y la mujer dice que:

«Si extraneus pro muliere dotem dedisset, et pactus esset,ut quoquo modo finitum esset matrimonium, dos ei redderetur, nec fuerint nuptiae secutae, quia de his cesibus solummodo fuit conventum qui matrimonium sequuntur nuptiae autem secutae non sint, nuptiae autem secuti, non sit, quaerendum erit utrum mulieri condictio, an ei, qui dotem dedit, competat? Et verisimile est, in hunc quoque casum eum, qui dat, sibi prospicere inam quasi causa non secuta habere potest condictionem, qui ob matrimonium dedit, matrimonio non copulato; nisi forte evidentissimis probationibus mulier ostenderit, hoc eum ideo fecisse, ut ipsi magis mulieri, quam sibi prospiceret $\rangle^{59}$.

El mismo autor comenta el caso de una mujer, llamada Seya, que recibe una dote de un sujeto indeterminado para que la dé en su propio nombre, siempre que

56 LAURIA. La Dote Romana, Memorie Accademia di Sciencie Morali e Politiche, Nápoles, 1938 p. 19 y ss. señala sobre la dote que «un dono della fidantaza o del suo pater familias a nome di lei, in occassione del matrimonio cum manu, al marito o al suo pater familias». Añade que «la dote non é piú neccessariamente donazione, perché puó costituirsi in infiniti altri modi- legato, rinunzia ad acquistare un diritto- má é frequentemente donazione».

57 BONFANTE. Op.cit., p. 385 señala que «la parola dos, come é tuttavía riconoscible, ha radice comune con dare, donatio, e la sua correspondenza piú strettta con le parole greche dosis puó, ben indurre nell'opinione che essa gia natta nell'evo anteriore alla separazione delle stirpi grecho italiche. La sua relazione con donatio e ripetutamente confermata anche dagli etimologisti romani».

58 DAZA, M.J. y RODRÍGUEZ ENNES, L., Instituciones de Derecho Privado Romano, Alicante, 1993 , p. 409 ss.

59 D. $12,4,6$. 
se verifiquen las nupcias. Si éstas no se llevan a cabo, la persona que donó el conjunto de bienes tiene la actio reivindicatoria sobre el mismo ${ }^{60}$.

MARCELO es tajante a la hora de afirmar que la dote se puede constituir por donación:

"Eius nomine, quae libera videbatur, decem in dotem dedisti; eo casu habebis condictionem, quo habere potuisses, si mulieris liberae nomine dedisses, nec nuptiae secutae essent. Si manumissa nupserit, ita demum dos erit, si ea mente dedisti, ut quandoque secutis nuptiis dos esset; igitur si mulieri donaturus dedisti, dominus condicet, quemadmodum si eum qui sibi donaturus esset, mulier ipsam donare iussisset ${ }^{61}$.

Estas opiniones jurisprudenciales ponen de relieve que las personas, en época clásica, cuando constituyen o entregan una dote lo hacen al menos con animo donand $i^{62}$. No entramos aquí en analizar si la donación de la dote constituye un negocio jurídico que reúne todos los requisitos de aquélla: Es suficiente, como ha quedado demostrado, que la entrega de bienes se considera donación, por lo menos, en algunos casos. Cuando el padre entrega la dote a su hija es un anticipo en vida. Esto pone de relieve que los coherederos en la época que vamos historiando, y el magistrado, por lo menos en su fuero interno, exigen la aportación de bienes porque de algún modo ha habido un adelanto patrimonial del que no se han podido beneficiar ellos. Esta situación provoca una distorsión patrimonial entre unos y otros, y es análoga a la collatio emancipati. El principio de que algunos anticipos patrimoniales, entregados en vida por el ascendiente a sus descendientes, deben ser aportados a la masa hereditaria, no es clásico. Esta tesis se forja en el Bajo Imperio, consecuencia de la nueva visión familiar y hereditaria y cristaliza en una disposición imperial dictada por el emperador LEÓN en el año 472 d.C.:

\section{«... tam dos quam ante nuptias donatio conferatur...» ${ }^{63}$}

Si esta idea no cristalizó en época clásica fue porque los coherederos emancipados comienzan a disfrutar de la colación de la dote en el s. III d. C. ${ }^{64}$ y por la relación necesaria entre la colación y la sucesión intestada masculina, hecho que

60 D. 23,3,9, ULPIANO, Libro trigesimo primo ad Sabinum señala que «Si ego Seiae res dedero, ut ipsa suo nomine in dotem det, efficientur eius licet non in dotem sint datae: sed condictione tenebitur, quod si pro ea res ego dem, si quidem ante nuptias, interest qua condicione dedi, utrum ut statim fiant accipientis an secutis nuptiis...».

61 D. 23,3,59,2, ULPIANO, Libro XXXI ad Edictum afirma "Quodsi qui patri donaturus dedit, Marcellus Libro sexto Digestorum scripsit, hanc quoque a patre profectam esse; et es verum».

62 LAURIA, Art. Cit., p. 19 ss.

63 C. VI,20,17.

64 C. VI,20,4V. 
provoca la exclusión de todos los descendientes por linea materna, lo que significa que el círculo de sucesores beneficiarios de la colación no está todavía cerrado y, por lo tanto, la idea del adelanto patrimonial no se concibió aplicable a ambas líneas sucesorias ${ }^{65}$.

\subsection{De la Colación de la Dote Pretoria a la Colación Imperial}

La segunda parte de la declaración ulpianea de $D .37,7,1$, supone una evolución extraordinaria en el desarrollo de la collatio dotis. ULPIANO sostiene, que fue el emperador ANTONINO PIO, quien ordenó, por rescripto imperial, la posibilidad de que la hija heredera civil, participase en la sucesión intestada de su ascendiente paterno, siempre que colacione su dote:

«... Et hoc Divus Pius Ulpio Adriano rescripsit, etiam eam, quae non petierit, bonorum possessionem, ad collationem dotis per arbitrum familiae erciscundae posse compelli» ${ }^{66}$.

A partir de esta disposición imperial, sí es plausible la idea de que esta nueva dimensión jurídica del instituto sea obra del trabajo de los juristas clásicos, desde las cancillerías imperiales. El enriquecimiento del Edicto Julianeo, la extensión de la nueva competencia al iudex familiae erciscundae, la ruptura de la exclusividad de la bonorum possessio, no se puede dudar que sea obra de ellos ${ }^{67}$.

\section{RENUNCIA A LA COLACIÓN DE LA DOTE}

La pretendida equiparación entre los coherederos, por parte del Pretor, quiebra con la simple renuncia de la mujer a ejercitar sus derechos en la sucesión intestada. Si la hija no solicita la posesión de los bienes hereditarios o ejerce el ius abstinendi, como heredera civil, no está obligada a colacionar a sus hermanos la dote. Por este motivo TRIFONINO afirma que:

«Fuit quaestionis an si, sua heres filia patri cum fratribus, contenta dote abstineat se bonis, compellatur eam conferre. Et hoc Divus Marcus Rescripsit, non compelli abstinentem se ab hereditate patris; ergo non tantum data apud maritum remanebit, se ab hereditate patris; ergo non tantum data apud maritum, remanebit, sed et promissa exigetur etiam a fratribus; et est aeris alieni loco, abscessit enim a bonis patris ${ }^{68}$

65 VOCI. Op. cit., p. 773 y ss.

66 D. $37,7,1$.

67 Vid. n. 38.

68 D. $37,7,9$. 
La razón de este principio general está en el hecho de que la ausencia de la hija, del concurso hereditario, no reduce ningún derecho hereditario de sus hermanos, y por ello ULPIANO afirma categóricamente:

«Si filia fuerit heres instituta, collatione dotis non fungetur; ... quoniam nullam inuriam fratri facit, non debere eam dotem conferre... ${ }^{69}$.

\section{SUJETOS DE LA COLLATIO DOTIS}

\subsection{Sujetos Activos}

1.- El Derecho romano clásico no imponía a cada una de las hijas dotadas, que sucede a su padre o un ascendiente paterno, la obligación de conferir la dote a sus coherederos. Existen dos regímenes distintos según sea o no instituida heredera.

2.- La hija dotada instituida heredera y la collatio dotis. ULPIANO en el Libro IV Disputationum, afirma que la hija instituida heredera está dispensada de la collatio dotis.

«Si filia fuerit heres instituta, collatione dotis non fungetur ... $»^{70}$.

Se trata de precisar que la hija instituida heredera no está obligada a la collatio dotis, cuando, después de la petición de uno de sus hermanos, ella había aceptado la bonorum possessio contra tabulas: unde si commisso ab altero edicto (necesse habuerit) contra tabulas bonorum possessionem (accipere). Es más, si por error había pedido la sucesión ab intestato, ignorando su designación como heredera, dice PAPINIANO que no estaba obligada a la collatio dotis, porque la hija patris voluntatem fini virilis partis retineat ${ }^{71}$.

Esta dispensa de colacionar por parte de la hija, instituida heredera, no era absoluta. La regla no se aplica, por ejemplo, cuando el padre imponía a su hija la collatio dotis como condición de su participación en la sucesión $(D .37,7,8)$, o cuando la parte hereditaria que la hija obtenía en la sucesión pretoria era superior a la que la confería el testamento ( $D .37,7,3 ; D .37,7,5$, pr. etc.).

Hay otra excepción concerniente a la hija dada en adopción, e instituida heredera por su padre legítimo. La institución de heredera era condición para la admisión a la sucesión pretoria, pero no confería a la hija, dada en adopción, las mismas ventajas que a otra hija. Efectivamente, la hija dada en adopción e instituida heredera, cuando era admitida a la sucesión pretoria contra tabulas, era
69 D. $37,7,3$.
70 D. $37,7,3$.
71 D. $37,7,5$. 
asimilada a la hija emancipada no instituida heredera, y, como ella, estaba obligada a colacionar los bona sua y la dote:

«filia in adoptionem data et heres instituta debet, sicut emancipata, non solum bona sua, sed et dotem... conferre» ${ }^{72}$.

La regla enunciada por ULPIANO, a la que anteriormente nos hemos referido, referente a la dispensa de la hija instituida heredera de colacionar la dote, fue confirmada por un rescripto de FELIPE en el año 246 (C. VI,20,7). El emperador LEÓN, en su famosa Constitución del 472 , donde instaura la collatio descendentium, vuelve a precisar que la dote no se debe más que en caso de sucesión $a b$ intestato. El emperador JUSTINIANO mantuvo el mismo régimen en las constituciones del 528 a 532 (C. VI,20,19; VI,61,6). Pero en la Novela 16 del año 536, modificó el antiguo sistema. En adelante, la hija instituida heredera, dentro del marco de la collatio descendentium, deberá colacionar la dote a sus coherederos, a no ser que fuese expresamente dispensada: nisi expressim designavit, velle non fieri collationem ${ }^{73}$.

3.- La hija dotada no instituida heredera y la collatio dotis.

La hija dotada no instituida heredera, llamada a la sucesión paterna por derecho civil o pretorio, en principio, estaba obligada a la collatio dotis. Si no había hecho la bonorum possessionis petitio, o si habiéndola hecho, no la había obtenido, estaba dispensada de colacionar la dote. Se discutió si una hija dotada, heres sua, llamada a la herencia paterna podía librarse de la collatio dotis si empleaba el ius abstinendi. TRIFONINO respondió afirmativamente:

«Divus Marcus rescripsit, non compelli abstinentem se ab hereditate patris» ${ }^{74}$.

La collatio dotis, como afirma SZLECHTER, no se imponía a la hija dotada más que en la medida en que era llamada a la sucesión paterna en virtud del mismo derecho que sus coherederos, de lo contrario, estaba dispensada:

«nec ipsa dotem fratribus suis conferet, cum diverso iure fratres sunt heredes» ${ }^{75}$.

72 D. $37,7,2$.

73 Nov. 16 c. 16 (536): ... sed sive quispiam intestatur moriatur seu testatus... omnino esse collationes.

$74 \quad$ D. 37,7,7; también D. 29,2,57.

75 D. $37,7,7$. 
Podemos decir, de un modo general, que la obligación de la collatio dotis, no se imponía a la hija dotada más que cuando, por su participación en la sucesión, perjudicaba a sus coherederos (iniuriam fratribus facit) y es aquí donde hay que buscar el fundamento de la institución ${ }^{76}$.

Como vimos anteriormente, ULPIANO en su libro XL ad Edictum, nos aporta los principales textos que conciernen al origen de la collatio dotis: $D .37,7,1 \mathrm{pr}$. y D. $37,7,1,8$.

Los autores antiguos consideraban que la collatio dotis, en el sentido preciso del término, es decir la collatio de la hija in potestate, tuvo su origen con ANTONINO PIO. FEIN, partiendo de la autenticidad del texto de ULPIANO (D. $37,7,1$. pr.), dedujo el origen pretorio de la collatio dotis y rechazó esa teoría. El edicto del Pretor concierne, según él, a la hija in potestate que pide la bonorum possessio... El emperador ANTONINO PIO extendió esta medida a la sucesión civil $^{77}$. Los autores modernos sostienen la doctrina de FEIN, no obstante las objeciones formuladas por BESELER sobre la autenticidad del texto ulpianeo ${ }^{78} \mathrm{y}$ que, en su día, fueron rechazadas por LENEL ${ }^{79}$.

Según FEIN, la collatio dotis sólo se aplica a la hija in potestate, ya que considera que el término filiam de la frase «ad collationem dotis praetor cogat filiam» designa necesaria y exclusivamente a la hija in potestate; porque, según él, la misma palabra es el sujeto de la segunda frase: (filia) attamen si non petat conferre debebit, si modo se bonis paternis misceat, que atañe a la sucesión civil. ULPIANO, añade FEIN, así lo indica, porque pone él mismo sujeto en las dos proposiciones.

La interpretación del edicto pretorio, propuesta por FEIN, no nos parece exacta. ULPIANO nos dice que... ad collationem dotis praetor cogam filiam, si petat bonorum possessionem; lo que significa que, cada hija que pide la sucesión pretoria, está obligada a la colación de la dote. Nada nos indica que allí se trate únicamente de la hija in potestate. La hija esté in potestate o emancipata,si usa del derecho sucesorio pretorio, está obligada a la collatio dotis. La segunda frase precisa etsi non petat, conferre debebit, si modo se bonis paternis paternis misceat, es decir, aunque no pida la bonorum possessio, debe colacionar si no ha usado el ius abstinendi. El sujeto de esta segunda frase es simplemente filia, quae petat bonorum possessionem. Como dice SZLECHTER «l'interprétation du terme filia de cette seconde proposition, dans le sens de filia in potestate, résulte uniquement

76 D. 37,7,3: dicendum est, quoniam nullam iniuriam fratri facit, non debere eam dotem conferre. Cfr. GUARINO, Collatio Bonorum, 1937, p. 87 y ss.; Studia et Documenta, 1938, p. 521 y ss. SZLECHTER, La Collatio Dotis, p. 170, n. 17.

77 FEIN. Das Recht der Collation, 1842, p. 146 y ss.; 155 y ss.; 183 y ss.

78 Beiträge, 2, p. 52; 3, p. 39; 4, p. 157; cfr. PRINGSHEIM, Festschrift Lenel, p. 267; GUARINO, Collatio Bonorum, p. 198 y ss.

79 Das Edictum Perpetuum, 1927, 145 (p. 346), Cf. MONIER, Manuel, I, 1949, p. 510; ARANGIO-RUIZ, Istituzioni, p. 540. 
de cette circonstance que, seule, la filia in potestate peut succéder d'aprés le droit civil a son père. Mais il n'y a aucune raison valable de rapporter cette qualification à la fille qui demande la succession prétorienne de la première proposition $»^{80}$.

Como consecuencia de lo afirmado anteriormente, pensamos que la collatio dotis pretoria no era sinónimo de la collatio dotis de la hija in potestate; el edicto del pretor imponía la colación de la dote a la hija que pedía la bonorum possessio, estuviera emancipada o in potestate; ANTONINO PIO extendió esta obligación a la hija que se sometía al derecho sucesorio civil.

\subsection{Sujetos Pasivos}

\subsubsection{Normativa de Antonino Pio}

El Edicto del Pretor que instauró la collatio dotis en la sucesión pretoria, así como el rescripto del emperador ANTONINO PIO que extendió la medida a la sucesión civil, no indicaban expresamente cuáles fueran los beneficiarios de la collatio dotis. Un principio negativo, de tipo general, nos es facilitado por ULPIANO, en el libro IV Disputationum:

«Si filia fuerit heres instituta, collatione dotis non fungetur; unde si commisso ab altero Edicto necesse habuerit contra tabulas bonorum possessionem accipere, dicendum est, quoniam nullam iniuriam fratri facit, non debere eam dotem conferre $»^{81}$.

Por consiguiente $\mathrm{y}$, en aplicación del principio ulpianeo, la hija no debe colacionar la dote a aquellos de sus hermanos y hermanas, a los que no perjudica su participación en la sucesión paterna. Entre ellos se encuentran, en primer lugar, los hermanos emancipados. Por el contrario, debe colacionar la dote con sus hermanos y hermanas in potestate llamados a la sucesión paterna, ya en virtud del derecho civil, ya en virtud del derecho pretorio; porque, por su participación, disminuye su pars hereditaria.

\subsubsection{Los Emancipados y la Collatio Dotis}

Los jurisconsultos clásicos, como sucedía con la collatio bonorum, no han afirmado de forma explícita la exclusión de los emancipados de la collatio dotis. ULPIANO, sin embargo, de una forma menos directa, en el libro XL ad Edictum, enuncia la misma regla para la collatio dotis:

80 SZLECHTER. La Collatio Dotis, p. 178.

81 D. $37,7,3 ;$ D. $37,6,1,3 ; 4 ; 5 ; 6 ; 7$. 
«Portiones collationum ita erunt faciendae, utputa duo sunt filii in potestate, unus emancipatus habens trecenta, ducenta fratribus conferet, sibi centum; facit enim iis partem, quamvis is sit, cui conferri non solet. Quodsi duo sint filii emancipati habentes trecenta, et duo in potestate, aeque dicendum est, singulos singulis, qui sunt in potestate, centena conferre, centena retinere, sed ipsos invicem nihil conferre. Dotis quoque collatio in eundem modum fiet, ut, quicumque confert, etiam suam personam numeret in partibus faciendis» ${ }^{82}$.

ULPIANO, en este texto, después de haber afirmado que los emancipados no colacionan sus bienes entre ellos, añade: dotis quoque collatio in eundem modum fiet. El pasaje se termina con las siguientes palabras: ut quicumque confert etiam suam personam numeret in partibus faciendis, lo que restringe el alcance de la frase anterior.

El texto de ULPIANO no nos parece que haya sido totalmente interpolado, más bien pensamos que haya sido retocado por los compiladores justinianeos en su parte final y que, en lugar de su redacción actual, estaría escrito del modo siguiente: filia quae dotem suam confert, etiam suam personam numeret in partibus faciendis.

La exclusión de los emancipados del beneficio de la collatio dotis se deduce igualmente, aunque de un modo indirecto, de dos textos del Digesto, uno de PAPINIANO (D. 37,7,5, pr.) y otro de ULPIANO (D. 29,4,23). Los dos jurisconsultos niegan la colación de la dote al hijo in potestate, instituido heredero, que concurre a la sucesión paterna con su hermana, igualmente instituida heredera. Estos autores no se pronuncian a propósito de la collatio dotis de la emancipada que interviene en la misma sucesión. Es probable que para los dos jurisconsultos la exclusión de los emancipados de la collatio dotis era un principio adquirido, y no juzgaban necesario, hablar de él.

ALEJANDRO SEVERO confirmó esta regla, en un rescripto del año 230 (C. VI, 20,3): ... dotem sane quam accepit fratribus qui in potestate manserunt conferre debet.

\subsubsection{Normativa Modificativa de Gordiano}

Una cuestión interesante es conocer si el estatuto jurídico de la collatio dotis fue modificado por GORDIANO.

La doctrina dominante así lo admite ${ }^{83}$. GORDIANO en una constitución del año 239, C. VI,20,4, habría concedido a los emancipados la dos profectitia:

82 D. $37,6,1,24$.

83 Hasta 1933, la doctrina había sido unánime en reconocer la autenticidad del texto de GORDIANO, y por consiguiente consideraba que, después del 239 , los emancipados tenían igualmente derecho a la collatio dotis, pero solamente a la dote profecticia. En 1933, ALBERTARIO, en Studi di Diritto romano, $I$, p. 289 , rechaza toda la segunda parte de la constitución de GORDIANO como interpolada. 
"Filiae dotem in medium ita demum conferre coguntur, si vel ab intestato succedant vel contra tabulas petant: nec dubium est profectitiam seu adventitiam dotem (a patre datam vel constitutam g.1) fratribus qui, in potestate fuerunt, conferendam esse. His etenim, qui in familia defuncti non sunt, profectitiam tantummodo dotem post varias prudentium opiniones conferri placuit.

La primera parte afirma que la filia sua confiere a los sui la dos profectitia y la adventitia. La segunda parte afirma que la fiia sua confiere a los emancipados solamente la dos profectitia. Este último punto es el que debe ser considerado para ver las razones que lo justifican:

a) El hermano emancipado tiene la carga de la collatio bonorum en favor de la hermana que ha permanecido in potestate. Es equitativo un régimen de reciprocidad, por el cual la hermana está obligada a conferir la dote.

b) El reconocimiento de esta exigencia cambió profundamente la estructura de la collatio, que de ser un instituto introducido como una carga del emancipado, se convierte en una institución predispuesta también en su favor.

c) Se comprenden, por tanto, las varietates jurisprudenciales, a las que, demasiado sumariamente, alude la constitución. Esta debió de ser la solución totalmente negativa: los emancipados no tienen derecho a la collatio dotis. Superada esta opinión, se planteaba el problema, si limitar la collatio a la dos profectitia o extenderla a la adventitia. La extensión total tenía a su favor, como dice $\mathrm{VOCI}^{84}$, un argumento nada despreciable: la parificación de principio de los emancipados a los sui, conducía a tratar, también en esta ocasión, a los primeros como a los segundos. Pero por otra parte, podía hacerse valer otra analogía. En la collatio bonorum, el emancipado no confiere al emancipado, es decir, el emancipado se limita a conseguir aquello que procede del padre, no se puede, pues, concederle un tratamiento distinto en perjuicio de la hermana, extendiendo los límites de una admisión, que ya es excepcional.

Consiga, por consiguiente, el emancipado solamente la dote profecticia.

Si todo esto es verdadero, en la collatio de la filia sua en favor del emancipado no hay que ver un principio que precede la collatio postclásica: la carga de conferir cuanto procede del ascendiente común a quien se sucede. Como afirma VOCI, «questo principio pressupone un mutamento nel regime patrimoniale della famiglia, che al tempo di GORDIANO e ancora sconosciuto. Puttosto e da pensare, como si é detto, á un onere de reciprocitá, che si retiene equo introduire ${ }^{85}$.

84 VOCI. Diritto Ereditario romano, I, Milán, 1967, p. 770.

85 VOCI. Op.cit. p. 770. 


\subsubsection{Opinión de Albertario y Pringsheim}

En un estudio aparecido en Studia et Documenta, vol. IV, en 1938, titulado Die Collatio dotis an die emancipati, M. PRINGSHEIM ha desarrollado y justificado la teoría de ALBERTARIO, expuesta en Studi di Diritto Romano I, p. 289 y ss., por la que se rechaza toda la segunda parte de la constitución de GORDIANO por estar interpolada.

La teoría de PRINGSHEIM está fundada sobre tres tipos de argumentos:

a) Sobre el análisis de la constitución:

Las palabras etenim, tantumodo pertenecen particularmente al vocabulario de TRIBONIANO, el empleo de sunt parece incorrecto, la expresión varias prudentium opiniones es una fórmula usada por los compiladores; conferri está mál situado.

b) Sobre las disposiciones de ALEJANDRO SEVERO (C.VI,20,3): Al decir de GORDIANO, su decisión fue tomada «post varias prudentium opiniones», ahora bien, señala PRINGSHEIM, no existe divergencia alguna, en los textos clásicos, con respecto al sujeto de la collatio dotis en favor de los emancipados. Es más, apenas nueve años antes, ALEJANDRO SEVERO reafirma el principio de la exclusión de los emancipados. DIOCLECIANO, en el año 294 precisa, a su vez, que sólo los hermanos in potestate se pueden beneficiar de la collatio dotis y no hace alusión alguna a los emancipados: ... fratribus in eadem familia constitutis ... En estas condiciones, afirma PRINGSHEIM, hay que admitir que la segunda parte de la constitución está interpolada.

c) Sobre la interpretación de los escolios de TALALEO al $C$. VI,20,3 y $C$. $V I, 20,12$.

En cuanto a la época de la interpolación, este autor la sitúa en época de JUSTINIANO. El texto no estaba todavía reelaborado en la primera edición del Código; la interpolación tuvo lugar en el Codex repetitae praelectionis. En efecto dice PRINGSHEIM, TALALEO en el escolio al C. VI,20,3, declara: «dynatai qar eipein apo tes diataseos tautes, oti adelphne autesousious anankasetai ten proika syneisenegkein touto de saoesteron mathe, kai ek eponenes diataseos» ${ }^{86}$, y en el escolio al C.VI.20,12, añade: «blepe oti kai auten e oiatasis toisypesousiois monois legei ginesthai ten syneisgoran ${ }^{87}$.

Si la interpolación de la constitución de GORDIANO estaba ya en la primera edición del Código, TALALEO no habría podido afirmar que los emancipados son excluidos de la colación de la dote, particularmente por la constitución de GORDIANO.

86 Bas. 41, VII, XXI, vol. 4, p. 176; ms. grec 1345, fol. 102 verso.

87 Bas. 4l, VII, XXVII, vol. 4, p. 177. 


\subsubsection{Crítica de la Opinión de Albertario y Pringsheim}

No nos convencen los argumentos anteriores y por ello, creemos con SZLECHTER $^{88}$, que no se puede rechazar, como interpolada, la segunda parte de la constitución de GORDIANO, en virtud de los argumentos siguientes:

a) Con respecto a los indicios formales de interpolación, es necesario subrayar que etenim, como conjunción, pertenece al vocabulario clásico; el que los compiladores la empleen con frecuencia no la puede privar de ese carácter. ¿Está bien usada en el texto? Pensamos que sí. GORDIANO declara en primer lugar: nec dubium est que la dote profecticia y adventicia deba ser conferida fratribus qui in potestate sunt, posteriormente introduce una idea de alcance más reducido y que, por consiguiente, es diferente de la precedente. Para explicarla y señalar el motivo, emplea etenim, lo cual es correcto. Puede que «tantummodo» se haya añadido para subrayar mejor la diferencia entre esta proposición y la precedente: profectitiam tantummodo dotem, por oposición a profectitiam seu adventitiam dotem.

b) La frase post varias prudentium opiniones está interpolada; sin embargo, no invalida la autenticidad de la decisión de GORDIANO, que ha sido tomada después de consultar a los jurisconsultos que formaban parte del consejo imperial, cuyas opiniones, no obstante, eran divergentes ${ }^{89}$.

Es verdad que nueve años antes de la constitución de GORDIANO, ALEJANDRO SEVERO declara: ... dotem... fratribus qui in potestate manserut, conferre debet. GORDIANO habría podido decir lo mismo en vísperas de su constitución. La referencia al rescripto de ALEJANDRO SEVERO puede servir, más bien, contra la opinión de PRINGSHEIM. En efecto, ALEJANDRO SEVERO emite un rescripto que, nada o casi nada, tiene de común con la collatio dotis. Decide la nulidad de la cláusula inserta en el contrato de constitución de dote, según la cual la dote debe reemplazar la parte sucesoria de la hija dotada.

La constitución de DIOCLECIANO, del 294, precisa que ... filiae... si dotem non conferat, quam mortis tempore communis patris habuit, fratribus in eadem familia constitutis ...; no hay duda que DIOCLECIANO habla únicamente de los hijos in potestate. Sin embargo, no debe verse una contradicción con la constitución de GORDIANO. La respuesta de DIOCLECIANO era conforme a la cues-

88 SZLECHTER, art. cit., p. 182 y ss.

89 Es muy probable que el texto original contuviera una fórmula análoga a la que nos da ULPIANO en $D .37,14,17 \mathrm{pr}$. y que hace referencia al rescripto dado por SEVERO Y ANTONINO, precisamente después de la consulta de las iurisprudentes, cuyas opiniones eran divergentes. En lugar de una fórmula tan larga, como la que se contiene en $D .37,14,17$, y donde el emperador indica la divergencia de opiniones de los jurisconsultos, los compiladores habrían insertado la frase «post varias prudentium opiniones», que resume bien el procedimiento de consulta de los emperadores en época clásica. 
tión que le fue propuesta, y ésta bien puedo venir únicamente de los hermanos in potestate.

c) En realidad, el argumento más importante a favor de la teoría de PRINGSHEIM, está en el Escolio al C. VI,20,3. Después de haber declarado que, según la constitución de ALEJANDRO SEVERO, la hermana no está obligada a conferir la dote al emancipado, precisa que esto resulta más evidente de la constitución siguiente, que es precisamente la de GORDIANO del año 239. La cuestión que se plantea es saber si la interpretación de este escolio, propuesta por PRINGSHEIM, es exacta, o al menos, la única posible. ¿TALALEO podría haberse expresado así en presencia del texto actual de la constitución de GORDIANO?

Es importante señalar, en primer lugar, que TALALEO comenta únicamente la constitución de ALEJANDRO SEVERO y no establece una regla general relativa a la collatio dotis. Es, según esta constitución, que la hermana no debe conferir la dote al emancipado. Ni que decir tiene que la regla es muy antigua y no ha sido creada por ALEJANDRO SEVERO. A continuación precisa que esto, es decir, el hecho de que esta constitución excluya a los emancipados de la collatio dotis, resulta todavía más evidente de la constitución siguiente que es la de GORDIANO, C. VI,20,4, porque sólo es esta última la que confiere a los emancipados la collatio dotis.

Supongamos, no obstante, que TALALEO tuvo presente, en el momento que comentaba el rescripto de ALEJANDRO SEVERO, la constitución de GORDIANO, en la que la parte relativa a la collatio dotis de los emancipados faltaba, puede preguntarse, con toda razón, qué hay en este texto que pusiera todavía más de manifiesto la exclusión de los emancipados. Por otra parte, si esta regla era tan evidente, no puede explicarse por qué TALALEO sentía la necesidad de buscar pruebas que pudieran justificarla.

SZLECHTER considera que debe atribuirse un gran valor a la interpolación de la constitución de GORDIANO y a la fecha de su inserción. El autor se pregunta por qué los compiladores concedieron a los emancipados únicamente la collatio de la dotis profectitia, excluyéndolos de la dos adventitia, y por qué esta interpolación quedó insertada en el codex repetitae praelectionis y no en la primera edición del Codex. A partir de la Constitución de LEÓN del año 472, la collatio dotis entra en el marco de la nueva institución conocida con el nombre de collatio descendentium. Las hijas dotadas debían colacionar la dote tanto a los hermanos in potestate, como a los emancipados: ut liberis tam masculini quam femenini sexus, iuris sui vel in potestate constitutis,... tam dos quam ante nuptias donatio conferatur ${ }^{90}$. 
Teniendo presente que PRINGSHEIM hace remontar la concesión de la collatio dotis a los emancipados a una fecha anterior a JUSTINIANO y que, aunque es discutible, fue LEÓN quien confirió a los emancipados únicamente la dos profectitia, dejando intacto el régimen antiguo relativo a la dos adventitia, distinción que desaparece en el derecho justinianeo, la pregunta que se plantea es en qué época ocurre esto. Parcialmente tuvo lugar en el año 529 (C. VI,61,6) y definitivamente en el año 532, esto es, después de la publicación de la primera edición del Codex (7 abril del 529) y antes de la publicación del Codex repetitae praelectionis (a. 534). Cabe preguntar entonces cómo puede concebirse esta posición de PRINGSHEIM, teniendo presente que se afirma la interpolación de una constitución para hacerle decir lo contrario.

En otras palabras, no puede creerse que esta interpolación viniera de alguien que no conociera la collatio dotis adventitia. Habría podido concebirse que la interpolación se hubiera producido antes de la constitución de LEÓN del a. 472, o bien antes de las constituciones de los años 529 y 532, en la época en que el régimen establecido por LEÓN todavía estaba en vigor. Pero, después de las modificaciones aportadas por estas últimas constituciones citadas, sería muy difícil comprender el interés de una interpolación contraria al estado contemporáneo del derecho.

Teniendo en cuenta esta argumentación, entendemos que debe aceptarse como válida la conclusión a que llega SZLECHTER, según la cual, la segunda parte de la constitución del a. 239 (C. VI,20,4), desde His etenim hasta el fin, que concede a los emancipados la collatio dotis adventitia, proviene de GORDIANO. El texto ha podido ser manipulado, pero lo cierto es que el nuevo régimen de la collatio dotis fue obra del emperador GORDIANO. Desde la constitución de LEON del a. 472 , la hija dotada debía colacionar, en la sucesión del ascendiente a todos sus hermanos y hermanas, sin distinción, la dote que ella había recibido de ese ascendiente ${ }^{91}$.

\subsection{Los Sui y la Collatio Dotis}

Los beneficiarios de la collatio dotis eran los coherederos de la hija adoptada que in potestate patris fuerunt (sunt), y a los que ella perjudica por su participación en la sucesión. Cuando la hija dotada concurre únicamente son sus hermanos y hermanas in potestate, colaciona con todos. Era completamente distinto cuando participaba en la sucesión del abuelo paterno, concurriendo con sus tíos y sus primos.

La nieta dotada, llamada a la sucesión de su abuelo, en la que participan igualmente su tío y su hermano, no colaciona más que a su hermano:

91 SZLECHTER. Art. cit. pp. 185-186. 
«si sit nepos et neptis ex eodem filio, et dotata sit neptis, sit et filius non pater eorum: neptis (omnem) dotem (soli) fratri collatura est $\rangle^{92}$.

Efectivamente, la participación de la nieta dotada en la sucesión de su abuelo, en concurso con su hermano, no perjudica a este último. El tío recibía la mitad de la sucesión, como habría recibido concurriendo con el hijo único de su hermano premuerto. Por el contrario, el hermano de la hija dotada vería su parte, en la sucesión, disminuida en la mitad. ULPIANO da la misma solución en la hipótesis en que la hija dotada esté emancipada:

«emancipata (autem) neptis dotem et bona sua (soli) nepoti (non etiam patruo) conferet $»^{93}$.

En este último caso, debe colacionar con su hermano, no solamente la dote, sino igualmente los bona sua.

La nieta dotada, hija única de su padre premuerto, llamada a la sucesión de su abuelo, en concurso con su tío y los herederos de un tío premuerto, debe colacionar la dote con todos sus coherederos:

«sed si sit neptis sola, non etiam nepos ex eodem, tunc confertur patruo, itemque nepoti vel nepti ex alio (filio)» ${ }^{94}$.

La nieta única recibe, en la sucesión de su abuelo, la parte que pertenecía a su padre: in patris locum succedere et eam partem habere.

Su participación en la sucesión perjudicaba a los otros herederos, y esto es lo que justifica la collatio dotis por su parte. En virtud del mismo principio, dos nietas, de hijos diferentes, llamadas a la sucesión de su abuelo en concurso con su tío, debían conferir la dote la una a la otra, y las dos a su tío: sed si duae neptes sint ex diversis filiis, conferent et invicem et patruo (D. 37,7,1,3). SZLECHTER encuentra dificultades en justificar la solución que da ULPIANO en el párrafo 4 in fine del fragmento $D .37,7,1$, - si ex eodem patre, tantum invicem conferent-. En efecto, el tío se beneficia de la collatio dotis de su sobrina, si es la hija única de un hermano premuerto. Lo cual es conforme al principio de la collatio dotis, porque la hija de su hermano premuerto, sustituyendo a su padre, recibe la parte de éste. ¿Por qué el tío es excluido del beneficio de la collatio dotis, cuando el hermano premuerto ha dejado dos hijas dotadas? Las dos, recibiendo la parte de su padre premuerto, disminuyen la parte de su tío. Este debía beneficiarse de la

\footnotetext{
92 D. $37,7,1,2$.

93 D. $37,7,1,2$.

94 D. $37,7,1,3 ;$ D. $37,8,1,16$.
} 
dote en la misma proporción que el patrimonio de su padre se había empobrecido, por la constitución, no de una, sino de dos dotes ${ }^{95}$.

La solución de ULPIANO, nos parece que se opone, a la que da CELSO en un caso análogo:

«si nepotes in locum filii successerunt, una portio his conferri debet, uti bonorum possessionis unam partem habeant; sed et ipsi ita conferre debent, quasi omnes unus essent» ${ }^{96}$.

Así, en la hipótesis examinada por ULPIANO, al suponer que las hijas dotadas estaban emancipadas, debían conferir a su tío los bona sua, ya que no hay razón para que estuvieron exentas de conferir la dote. PAULO, en el libro XLI ad Edictum (D. 37,6,2,7) admite, también él, la obligación de colacionar en un caso análogo, los bona sua. Parece que ULPIANO examina en el párrafo 4 in fine la hipótesis de dos hijas dotadas llamadas a la sucesión de su padre, o de su abuelo, y regula únicamente las relaciones entre ellas. Siendo esto así, se puede explicar el empleo de la expresión: si ex eodem patre, en lugar de: si ex eodem filio ..., que concordaría con ex diversis filiis si las dos proposiciones debían referirse al mismo caso. Pensamos que el fin del párrafo 4 está completamente interpolado.

\section{OBJETO DE LA COLLATIO DOTIS}

\subsection{La Dote en el Derecho Preclásico y Clásico. Observaciones Generales}

El término dos está, etimológicamente hablando, en conexión con do y dono, de modo que se relaciona con la concepción originaria de la dote como un don que la nubenda ( o el paterfamilias de la misma) hace al marido o al paterfamilias de éste. El término dos fue el nombre del instituto a lo largo de las diferentes épocas de su historia, aunque en una época más reciente aparece junto a él también el término res uxoria, que era la dote en cuanto objeto de una obligación de restitución por parte del marido y que surgía al disolverse el matrimonio.

La presencia de esta obligación permite a la dote pasar a ser un modo de asegurar a la mujer los medios para su subsistencia después de que cesaba el matrimonio. Como observa CANNATA ${ }^{97}$, al lado de estos modos de considerar la dote, en estrecha conexión con su régimen jurídico, se pone también el que se deriva de su función social. Bajo este punto de vista, la dote era un patrimonio que la mujer aportaba a la nueva familia para contribuir a sostener los onera matrimonii (D. $23,3,56,1)$. Aunque esta concepción no tenía consecuencias jurídicas, no

95 SZLECHTER. Art. cit. p. 187.

96 D. $37,6,7$.

97 C.A. CANNATA, art. dote, «Enc. Dir» XIV (1985), p. 1. 
puede pasarse en silencio, porque es muy conocido el hecho de que toda la materia relacionada con el matrimonio y la familia acusaba profundamente las reglas y costumbres extrajurídicas que contribuían a determinar el perfil de los distintos institutos.

Ateniéndonos al punto de vista jurídico, correspondía al marido la propiedad de los bienes dotales. Las atenuaciones que las consecuencias prácticas de este principio fueron teniendo lugar, confirman su persistente validez. Piénsese, por ejemplo, en la disposición de la lex Julia de fundo dotali, que prohibió al marido (y a sus herederos, según recuerda PAULO), enajenar sin el consentimiento de la mujer, el fundo itálico, tanto urbano como rústico ${ }^{98}$, comprendido entre los bienes dotales, con la consecuencia de hacer que la eventual enajenación fuera ineficaz en relación con la mujer; o piénsese también, por ejemplo, en la disposición análoga de la lex Julia de maritandis ordinibus que prohibió al marido manumitir a un esclavo dotal, sin el consentimiento de la mujer. Es significativo, en este sentido, el siguiente pasaje de PAPINIANO:

«Dotalem servum vir invita uxore manumisit; heres solus vir a liberto institutus portionem hereditatis, quam ut patronus consequi potuit ac debuit, restituere debet, alteram vero portionem dotis iudicio, si modo uxor manumittenti refragatur» ${ }^{99}$.

\subsection{La Constitución de la Dote}

Para la constitución de la dote existía en Roma un negocio típico denominado dotis dictio y que consistía en un acto formal que se concluía verbis, uno loquente. Este negocio tenía un carácter obligatorio, tal como ha expuesto KASER ${ }^{100}$ oponiéndose a la tesis mantenida por LAURIA ${ }^{101}$.

La posibilidad de dotem dicere la tenían únicamente el paterfamilias de la mujer y la mujer misma (nuptura) si era sui iuris (teniendo, como es lógico, la auctoritas tutoris $)^{102}$, o bien el deudor de ella si realizaba el acto con su autorización ${ }^{103}$.

En la doctrina romanística se ha discutido ampliamente si la dotis dictio estaba originariamente relacionada con el matrimonium cum manu, o bien con el matrimonio libre. Como subraya CANNATA, es claro que, si se admite el efecto

98 D. $23,5,1 \mathrm{pr}$

99 D. 24,3,61; cf. también D. 24,3,62 y D. 24,3,63.

100 KASER. Die Wirkungen der «dotis dictio», S.D.H.I, 1951.

101 LAURIA. La Dote Romana, en Atti dell'Academia delle Scienze di Napoli, 1937, p. 219 y ss.

102 Cf. ULPIANO. Tit. II, 20; GAYO, I, 178.

103 Cf. ARCHI, Dote e donazione nel diritto romano, en Studi in memoria di Albertario, II. 1953 , p. 233 y ss. 
obligatorio de la dictio, en el sistema de la manus no pueden tener sentido los casos de dote constituida por la mujer o por su deucior, ya que al menos estos dos están referidos al matrimonium sine manu $^{104}$.

En las fuentes se alude a otros modos de constitución de la dote que eran atípicos: datio y promissio dotis, aunque éstos no son los únicos modos posibles de constitución, ni, por otra parte, se refieren sólo a dos negocios específicos. En efecto, si la promissio dotis, que se realizaba en forma de stipulatio era $\mathrm{el} \mathrm{modo}$ característico de la constitución de la dote con efecto obligatorio, este mismo efecto podía alcanzarse mediante legatum per damnationem. He aquí, por ejemplo, un texto significativo de JULIANO:

Socer genero suo legaverat: "Luicio Titio filiae meae nomine centum heres meus damnas esto dare»; hanc pecuniam generum petere debere, exactam acceptam legatis referri, sed divortio facto de dote actionem mulieri reddendam Proculus respondit, et nihilominus dotis esse factam. Iulianus notat: imo nec filiae, si voluerit, deneganda est huismodi actio $^{105}$.

Hay que tener presente además que se entendía por datio dotis cualquier acto con un efecto real (traditio, mancipatio, in iure cessio) empleado en el momento de la constitución de la dote con la finalidad de transferir los bienes dotales en propiedad al marido. Si este era filius familias, podia constituirse la dote en favor del pater, sobre el que gravaba totalmente la obligación de la restitución. Esta misma consecuencia se producía si los bienes dotales se daban al filius, pero iussu patris. También era posible que la dote se constituyera en favor del filius, pasando los bienes dotales a formar parte de su peculium, caso en el que la obligación de restituir correspondía al filius, aunque podia hacerse valer en los limites del peculium contra el pater. He aquí como se expresa a este propósito ULPIANO:

«... Quodsi (dos) filio data sit non iussu patris, Sabinus et Cassius responderunt, nihilominus cum patre agi oportere; videri enim ad eum pervenisse dotem, penes quem est peculium; sufficit autem ad id damnandum, quod est in peculio, vel si quid in rem patris versum est. Sin autem socero dotem dederit, cum marito non poterit experiri, nisi patri heres extiterit» ${ }^{106}$.

Hay que tener presente, finalmente, que la eficacia de la constitución de la dos estaba en conexión con la constitución del vínculo matrimonial, en el sentido de

104 C.A. CANNATA, Art. cit. p. 2.

105 D. $23,3,48,1$.

106 D. $24,3,22,12$. 
que la dote constituida antes del matrimonio, no tenía efecto si no seguía un matrimonio válido para el derecho civil. $\mathrm{Si}$ el matrimonio no se realizaba posteriormente y las cosas dotales habían pasado ya a ser propiedad del marido (datio dotis), el que constituía la dote podía exigirla con la condictio ${ }^{107}$.

En el Derecho Romano clásico, se distinguía entre la dos profectitia, es decir la constituida por el paterfamilias de la mujer y, más tarde, también por el progenitor de la hija emancipada, y la dos adventitia, constituida por cualquier otra persona. Finalmente, existía la dos receptitia, esto es aquélla cuyo constituyente ha acordado, en el momento de la constitución, la restitución a él mismo en el caso de que el matrimonio se disuelva por muerte de la mujer.

\subsection{La Restitución de la Dote}

Supuesto que la eficacia del acto constitutivo de la dote estaba relacionado con el hecho de que surgiera el vínculo matrimonial, cuando éste cesaba, no influía, en la época antigua, sobre la suerte de los bienes dotales, que quedaban definitivamente en el patrimonio del marido. Este sistema tenía como consecuencia el que la mujer quedara definitivamente privada de los bienes dotales, no pudiendo recuperarlos al disolverse el matrimonio, ya ocurriera esto por divorcio o por muerte del marido ${ }^{108}$. A finales del S. III a.C., cuando comenzaron a multiplicarse los divorcios sin culpa de la mujer, tal situación aparecía como socialmente injusta.

Con el fin de hacer frente a estos inconvenientes se recurrió primeramente a las cautiones, mediante las cuales el futuro marido en el acto mismo de la constitución de la dote, se obligaba a restituir ésta en caso de divorcio o, tal vez, también en cualquier caso de disolución del vínculo, tal como pone de manifiesto ALFENO cuando dice:

«Aliud est, si pater pro filiam dotem promisit, ut annua, bima, trima, quadrima, quinto anno dos a se redederetur, et convenit, ut iisdem diebus dos soluto matrimonio redderetur; hoc enim pactum ita valet, si patri filia heres extitisset, et interveniente ea pactum conventum fuerit» ${ }^{109}$.

Supuestas las insuficiencias que tenía este sistema, a comienzos del S. II. a.C. se introdujo la actio rei uxoriae, que permitía conseguir la restitución de la dote, incluso si ésta no había sido prometida. Se discute entre los romanistas si era o no un iudicium bonae fidei, aunque es seguro que en la fórmula aparecían las palabras quod eius melius aequus erit, que capacitaban al juez para establecer lo que

107 D. $23,3,7,3$; cf. D. $12,4,6$.

108 Cf. S. SOLAZZI. La restituzione della dote in diritto romano, 1899, p. 379.

109 D. $23,4,19$. 
consideraba justo que se restituyera de la dote y para adaptar la condena a esa valoración ${ }^{110}$.

Es importante subrayar que las reglas que fue estableciendo la jurisprudencia a propósito de los límites de la obligación que tenía el marido de restituir la dote, se relacionan estrechamente con la actividad interpretativa que fueron haciendo los juristas a propósito del melius aequus de la fórmula citada. Dejando de lado las reglas que se refieren a las retentiones, hay que subrayar la importancia que tuvieron en otros ámbitos. Así, en caso de divorcio, la mujer tenía en relación con el marido crédito cuyo objeto era la dote. Si la mujer sui iuris moría después del divorcio, la actio se extinguía, a no ser que el marido estuviera in mora en la restitución, en cuyo caso el crédito se transmitía a sus herederos. Si la mujer estaba in potestate patris el ejercicio de la acción correspondía al pater, adiuncta filiae persona ${ }^{111}$. En caso de que el divorcio hubiera tenido lugar por culpa de la mulier o del paterfamilias de la misma, el marido tenia derecho a algunas retenciones (propter liberos, propter mores, etc.).

En el supuesto de muerte de la mujer, la actio rei uxoriae no correspondía más que a quien hubiera constituido la dos profectitia, si todavía estaba vivo. Así pues, en cualquier otro caso la dote permanecía en poder del marido, a menos que no fuera receptita. En caso de muerte del marido, la actio rei uxoriae correspondía a la mujer contra los herederos de él. Pero si el marido había mencionado a la mujer en su testamento, en virtud del Edictum de alterutro, contenido en el Edicto Pretorio ${ }^{112}$, la mujer podía, a su elección, atenerse a la disposición testamentaria o exigir la restitutio dotis.

\subsection{Dos y Actio Rei Uxoriae}

Como hemos expuesto anteriormente, la hija, durante el matrimonio, no dispone más que de un crédito (nomen) para la restitución de la dote, crédito exigible después de la disolución del matrimonio. Realmente se trata de un derecho sancionado por la actio rei uxoriae. Los derechos de la esposa, por una parte, y las obligaciones del esposo, por otra, en modo alguno fueron afectados por la participación de la esposa en la sucesión paterna y la obligación de la collatio dotis, si había lugar a ella.

Como nos pone de manifiesto C. VI,20,5 (a. 239) ni la fecha de su exigibilidad, ni el mismo objeto fueron modificados:

110 Cf. GROSSO. Ricerche intorno all'elenco classico dei «bonae fidei iudicia», en RISG, 1928, I, p. 39 y ss.

111 Cf. BURDESE. Dos patris et filiae communnis, Labeo, 1959, p. 284 y ss.

112 C. $V, 13,1,3$. 
«dotis quidem petitio perseverante matrimonio tibi non competebat; quamvis enim eam intestato patre defuncto, fratri conferre debueras, non tamen eo nomine adversus maritum tibi actio potuit esse...».

La collatio dotis, pues, tiene esencialmente por objeto la cesión de la actio rei uxoriae, único derecho en los instrumentos jurídicos de que puede disponer la mujer dotada ${ }^{113}$ durante el matrimonio, más bien que de la dote misma. El rescripto del emperador GORDIANO (C. VI,20,5), que acabamos de citar, precisa, en efecto, que la mujer no puede, perseverante matrimonio, intentar una dotis petitio contra su marido; y añade: quamvis enim eam (es decir la dotis petitio), intestato patre defuncto fratri conferre debueras.

Cuando ULPIANO emplea las expresiones: ad collationem dotis (D. 37,7,1), ... dos, collatio eius fiet (\& 1), ... dotem ... collatura est (\& 2); y GAY0: dotem conferre ... D. 37,7,2, u otras expresiones similares que se encuentran en otros juristas, hay que tener presente que siempre precisan que es el crédito resultante de la actio rei uxoriae lo que constituye en realidad el objeto de la collatio dotis y no la dote misma, que la mujer volverá a recuperar después de la disolución del matrimonio. En este sentido, es muy significativo el siguiente pasaje en el que ULPIANO hace suya la opinión que había expresado PAPINIANO diciendo:

«si filia nupta, quae dotem conferre debuit, per errorem coheredium ita cavit, ut quod a marito reciperasset, pro partibus hereditariis soveret, nihilo minus arbitrum familiae erciscundae sic arbitraturum Papinianus scribit, ut, etiam si constante matrimonio ipsa diem suam obierit, conferatur dos; (nam imperita inuit coheredum iurisdictionis formam mutare non potuit) ${ }^{114}$.

Ya se ha indicado anteriormente que la collatio dotis no cambiaba las obligaciones del marido relacionadas con la restitución de la dote, ya que él continuaba pudiendo prevalerse del benefitium competentiae. La hija dotada no estaba obligada a conferir más que la actio rei uxoriae, o más precisamente el crédito resultante de esa acción, no siendo, en principio, responsable de la insolvencia de su marido. Si después de haber garantizado a sus coherederos la collatio dotis, y después de la disolución de su matrimonio, ejercía la actio rei uxoriae, ella confería únicamente lo que había recuperado. He aquí como se expresa ULPIANO:

113 Cf. FEIN. Op. cit. p. 164 y ss.

114 D. $10,2,20$. 
«quodsi iam factum divortium est, et maritus non sit solvendo, non debebit integra dos computari mulieri, sed id, quod ad mulierem potest pervenire, hoc est, quod facere maritus potest ${ }^{115}$.

\subsection{Dos Profectitia y Dos Adventitia}

\subsubsection{Análisis de las Fuentes}

Del análisis de los textos que se encuentran en el Edicto del Pretor, en el rescripto de ANTONINO y en los escritos de los jurisconsultos clásicos no se puede precisar si el objeto de la collatio dotis era únicamente la dos profectitia o también la dos adventitia, si bien alguno de estos textos parecen dar a entender que era la dos profectitia ${ }^{116}$. Así, en un pasaje de PAPINIANO se dice: pater nubenti filiae quasdam res praeter dotem dedit ${ }^{17}$. De forma similar se expresan también TRIFONINO ${ }^{118}$ y ULPIANO ${ }^{119}$. Así pues, parece que una consideración general de los textos favorece la interpretación restrictiva de la palabra dos. En efecto, y tal como observa oportunamente SZLECHTER, no se explicaría fácilmente, por ejemplo, las razones por las que la nieta dotada por sus ascendientes maternos debía colacionar esta dote a su tío paterno, o incluso a los herederos de su tío premuerto ${ }^{120}$.

Pretender restringir el término dos a la dos profectitia únicamente, choca frontalmente con determinados textos que de forma indirecta, aluden a la dos adventitia. Así, GAYO observa que la hija dada en adopción e instituida heredera por su padre legítimo, debe colacionar, no sólo los bona sua, sed etiam dotem quae ad eam pertinere poterit ${ }^{121}$. Eliminando la dos receptitia, parece evidente que se debe interpretar la expresión quae ad eum pertinere poterit, como englobando tanto la dos profectitia como la adventitia. Parece poco probable que la expresión esté interpolada, ya que la tendencia que prevalece en el Bajo Imperio, particularmente después de la Constitución del emperador LEÓN y sobre todo a partir de JUSTINIANO, ya antes de la publicación del Digesto ${ }^{122}$, es más bien favorable a la noción de dos, en cuanto a la collatio. La obligación de colacionar, tanto la dos profectitia como la dos adventitia, concierne igualmente a

115 D. $37,7,1,6$; cf. también D. 37,7,1,5.

116 Para el Edicto del Pretor D. 37,7,1, pr; en cuanto a los escritos de los jurisconsultos clásicos, hay que aludir a GAYO $(D .37,7,2)$, PAPINIANO (D. $37,7,5,8)$, TRIFONINO $(D .37,7,9)$, y ULPIANO (D. 37,7,3).

117 D. 37,7,8; cf. también el pasaje de ULPIANO en D. 23,3,5 pr: profecticia dos est quae a patre vel (parente avo) (paterno avo) profecta est de bonis vel facto eius.

118 D. $37,7,9$.

119 D. $37,7,1,8$.

120 SZLECHTER. Art. cit. p. 190.

121 D. $37,7,2$.

122 Cf. C. VI,61,6 y C. VI,20,21 del a. 532. 
la hija emancipada que, de este modo, queda asimilada a la hija dotada y dada en adopción $^{123}$.

La misma regla es aplicada por ULPIANO también a la hija in potestate: si sub condicione pater vel extraneus dotem promiserit ... ${ }^{124}$.

\subsubsection{Opinión de Albertario. Crítica}

Estas consideraciones no han sido aceptadas por un sector de la doctrina, cuyo principal representante es ALBERTARIO, el cual sostiene que el Derecho Clásico no hace distinción entre ambas clases de dotes. Existe la dos profectitia y otra que no lo es, pero no le otorga el nombre de adventitia. Para este autor, la mujer, en época clásica, sólo debe colacionar la dos profectitia ${ }^{125}$. El ordenamiento prescribe que la filia sua colacione con sus hermanos heredes sui, pero no con los emancipados. ULPIANO, afirma ALBERTARIO, no puede haber señalado como dos adventitia la constituida por los terceros, porque la mujer puede constituirse la dote y no es extraña a su familia. Ella colaciona sólo aquello que proviene de los ascendientes paternos.

La tesis de ALBERTARIO nos parece poco probable por las siguientes razones:

1) En primer lugar las fuentes indican con claridad que la dote puede ser constituida por la mujer misma y por terceras personas. ULPIANO así lo reconoce en muchos textos, de los que puede ser un ejemplo el contenido en el Libro XXXIII ad Edictum:

«Si, quum dotem daret pater vel extraneus pro muliere, in unum casum pepigit, vel in divortium, vel in mortem, dicendum est, in eum casum, in quem non pepigit, esse mulieri actionem (D. 24,3,22).

La denominación que los jurisprudentes clásicos dieron a las diferentes clases de dote tiene mucha importancia. En sus escritos afirman que la dote adventitia puede ser constituida por sujetos unidos cognaticiamente a la mujer por línea ascendente paterna, por terceras personas, así como por la mujer misma.

2) No cabe duda que la mujer no es extraña a la relación familiar, desde un punto de vista de parentesco, si está bajo potestad. Sin embargo en la época del Principado, la emancipada es ajena al grupo familiar. La familia cognaticia plena comienza a desarrollarse a lo largo de esta etapa, donde la influencia de los pretores hace prevalecer las relaciones de cognación, que une a los seres que descienden de un tronco común. Desde un punto de vista sucesorio son extraños a la hija los ascendientes por vía materna, madre, abuela, tíos carnales, etc..

123 D. 37,7,2; ULPIANO confirma esta opinión en $D .37,7,1,1$.

124 D. $37,7,1,7$. 
Esta situación es idéntica en relación a los coherederos que no han estado bajo patria potestad. En estos momentos históricos comienza a darse solución a las distorsiones jurídicas que nacen del concurso de los emancipados en la herencia, pues, hasta ahora, los emancipados «familiam habent». Esta concepción hace que los romanos consideren al sui iuris como un extraño en relación a su grupo familiar. Toda esta problemática se supera con la intervención de los emperadores, a partir del S. III d. C. y encuentra su culminación con el nuevo tratamiento normativo que dan los compiladores bizantinos al derecho de familia y su nuevo régimen económico patrimonial.

3) GAYO a propósito de la extensión del legado sinendi modo señala que:

«... sed etiam heredis sui; cum alioquin per vindicationem nisi suam rem legare non potest, per damnationem autem cuiuslibet extranei rem legare potest ${ }^{126}$.

Este autor utiliza la palabra extraneus para indicar terceras personas. ¿Por qué los compiladores iban a tener interés en interpolar, con la palabra extraneus, todos los casos de constitución de dote por personas ajenas a la relación familiar? En esta línea SOLAZZI afirma al respecto: «Tuttavia io non asserisco che la locuzione vel extraneus sia totalmente spuria. Vi sono altre possibilitá, per. es. che extraneus abbia sostituito alius» ${ }^{127}$.

4) ULPIANO en $D .37,7,1,7$ hace alusión a terceras personas, «... Si sub conditione pater, vel extraneus dotem promiserit...», porque la promesa de entrega se lleva a cabo entre dos personas, el promitente oferente y el sujeto que recibe el compromiso, en este caso, la mujer. Esto no significa que ella se constituya su propia dote, porque la promesa es ofrecida bien por su paterfamilias, bien por otros sujetos. Si los constituyentes son los ascendientes por vía materna, la dos «non est a patre profecta», y por esto es, adventitia. Como la mujer en este caso es la receptora, no hay razón alguna para suponer que no debe aportar a la carga de la colación la dote adventicia.

\subsubsection{Doctrina Dominante}

La doctrina mayoritaria (FEIN, PRINGSHEIM, GUARINO, VOCI, SZLECHTER, etc.) afirma que el objeto de la collatio dotis comprende tanto la dos profectitia como la dos adventitia.

Esta tesis nos parece que está mucho más de acuerdo con los principios de Derecho Clásico relativos a la colación de la dote:

125 ALBERTARIO. Studi, I. p. 290.

126 GAYO. II. 210.

127 SOLAZZI. Pater vel extraneus, en «Scripti di Diritto Romano», IV. p. 180. 
1) Tal como nos ha llegado el texto del rescripto de GORDIANO los juritas del emperador mantienen que el paterfamilias constituye una dos adventitia, lo que es inconcebible en la etapa clásica, «... Nec dubium est, profectitiam seu adventitiam dotem a patre datam vel constitutam, fratribus, qui in potestate fuerunt, conferendam esse» ${ }^{128}$. Pensamos que esta glosa explicativa se debió al desconocimiento del derecho vigente por parte del jurista del Bajo Imperio.

2) Otra explicación se obtiene de la utilización, por extensión, de los principios de la collatio bonorum aplicados a la colación de la dote. Los emancipados aportan los bienes que recibieron de su padre en el momento de ser emancipados y aquellos que hayan obtenido en el ejercicio de sus negocios, por legados, o por otras causas, de terceras personas hasta el momento del fallecimiento de aquel.

GORDIANO confirma este principio tradicional, vigente para los emancipados, con una respuesta a través del rescripto dirigido a un tal CLAUDIO en el año 244 d.C., bajo los consulados de PEREGRINO y EMILIANO:

«Ea demum ab emancipatis fratribus his, qui manserunt in potestate, conferri consueverunt, quae in bonis eorum fuerunt eo tempore, quo pater fati munus implevit, exceptis videlicet, quae ab ipsis aliis debentur» ${ }^{129}$.

La hija goza de la libre disponibilidad de los bienes dotales constituidos por sujetos desligados del tronco común paterno. Esta premisa es, por analogía a la colación de los emancipados, un principio paralelo. La mujer es beneficiaria de una ventaja patrimonial que no recibe de su padre. Si participa con sus hermanos en la sucessio in ius reduce sus derechos hereditarios civiles, prevaliéndose de su peculiar situación matrimonial, (la dos es una ayuda para sostener el matrimonio). En ambas colaciones el magistrado observó la necesidad (aequitas) de equiparar a los coherederos, producto de las desventajas patrimoniales que unos irrogan a los otros. Esta situación, ratio que justifica la actuación honoraria, es completamente válida para la colación de la dote.

3) ALBERTARIO señala que los juristas clásicos hablan de dos profectitia y non profectitia. Si la hija aporta la primera ¿qué es lo que ocurre con la segunda? La mujer se beneficiaría de esa ganancia, fruto de su boda, y estaría exenta de cualquier responsabilidad sucesoria en favor de los demás coherederos. No es posible que el iusdicente, por principio de seguridad jurídica, no cubriera esta situación, cuando todos los principios de esta materia tienden precisamente a evitar estas arbitrariedades.

Si pensamos en los coherederos que han logrado la posesión de los bienes, esta situación les parecería intolerable frente a su hermana, pues, de un lado,

128 C. VI, $20,4$.

129 C. VI,20,6. 
resultan perdedores y, de otro, en la colación clásica no se atiende a la presunta voluntad del testador, principio que se consolida varios siglos más tarde con el emperador JUSTINIANO, que extiende la carga de la colación a la sucesión testamentaria.

4) Si aplicamos los principios jurídicos que hemos analizado al supuesto de la exención de la dos adventitia, tendríamos las siguientes consecuencias:

a) Si la hija es emancipada debería colacionar la dos adventitia a título de collatio bonorum, una vez que fallece el de cuius, sin embargo ya hemos demostrado que el Edicto recogió los títulos de un modo separado.

b) Otra conclusión es que la hija que permaneció bajo potestad está exenta de colacionar la dos adventitia, principio que está en contradicción flagrante con la normativa clásica que preside el instituto.

5) Si lo anterior es cierto, la colación produce otras situaciones anómalas:

a) El tío paterno de la hija se beneficia de la aportación dotal proveniente de los ascendientes maternos y de terceras personas. b) En el mismo caso saldrían beneficiados los primos hermanos nacidos de un tío premuerto:

«Sed et si duae neptes sint ex diversiis filiis, conferent et invicem, et patruo; si ex eodem patre, tantum invicem conferent ${ }^{130}$.

Podemos dar la explicación siguiente: La hija colaciona no sólo aquello que proviene por línea paterna, como ya hemos demostrado, del mismo modo que los emancipados no colacionan solamente los bienes que recibieron del padre, sino también los que obtuvieron de terceras personas. Bajo esta equiparación patrimonial se justifica el beneficio del que gozan los sujetos activos señalados con anterioridad.

6) Una última explicación simple se halla en el hecho de que los juristas consideran que la mujer puede colacionar porque tiene el derecho o la expectativa de recuperar su dote. Este es como hemos visto, el verdadero objeto collationis. Si esto es así, no podemos excluir de la carga de la aportación a la dos adventitia, presuponiendo además que el rescripto imperial de Gordiano está interpolado.

7) Una constitución de GORDIANO del año 239 confirma claramente la opinión dominante cuando dice:

«filiae dotem in medium ita demum conferre coguntur, si vel ab intestato succedant, vel contra tabulas petant; nec dubium est profectitiam seu adventitiam dotem a patre datam vel constitutam, fratribus, qui in potestate fuerunt, conferendam esse». (C.VI,20,4).

130 D. $37,7,1,4$. 
El análisis de este pasaje de GORDIANO pone de manifiesto que se está refiriendo al derecho que entonces estaba en vigor, esto es, no establecía una regla sino que constataba su existencia. Aunque el texto citado está ciertamente interpolado, la interpolación como afirma SZLECHTER, «ne concerne pas la disposition essentielle relative a l'objet de la collatio dotis» ${ }^{131}$. En suma, puede considerarse exacta la reconstrucción que hace GUARINO del texto propuesto y que es la siguiente:

«nec dubium est [profectitiam seu adventitiam] dotem a patre datam $v e l<a b$ extraneo $>$ constitutam fratribus qui in potestate fuerunt conferendam esse ... ${ }^{132}$.

La cuestión que se plantea es la de saber por qué los compiladores han retocado el texto antiguo. En efecto, no se excluye que la corrupción del texto original esté relacionada con el cambio del régimen de la collatio dotis bajo JUSTINIANO. En la época clásica la hija dotada debía colacionar, además de la dos profectitia, cualquier otra dos recibida de los parientes maternos, o de un tercero, o bien constituida por ella misma. La locución dos ab extraneo constituta era sinónima de dos aliunde quam ex re patris constituta (D.23,3,33). A partir de la constitución de LEON del año 472, la hija debe colacionar en la sucesión de su ascendiente, tal como se evidencia en este pasaje:

«tam dos... conferatur, quam pater vel mater, avus vel avin, proavus vel proavia, paternus vel maternus dederit vel promiserit pro filio vel filia, nepote vel nepte... cuius de hereditate agitur, eadem dos vel ante nuptias donatio ex substantia eius profecta conferatur ... ${ }^{133}$.

Esta regla es confirmada por JUSTINIANO en la constitución del año 528 en la que se lee:

«de collatione dotis vel ante nuptias donationis... quam defuncta persona pro filio vel filia..., dedisset; ...dotem... a parentibus sibi datam conferre ${ }^{134}$.

Lo mismo puede decirse de otro pasaje de una constitución promulgada al año siguiente, $y$ en la que se dice textualmente:

131 SZLECHTER, Art. cit., p. 191.

132 GUARINO. Op. cit. p. 521.

133 C. VI, $20,17$.

134 C. VI,20,19. 
«... dos a patre data vel matre vel aliis parentibus pro filio vel filia... conferre eam cogenda...» ${ }^{135}$.

La expresión dos adventitia designaba en JUSTINIANO, más particularmente, la dote que provenía de la madre o de los ascendientes maternos. Esta locución se adaptaba mejor a la empleada probablemente por GORDIANO (dos ab extraneo constituta) lo que podría explicar, quizá, por qué fue interpolada la constitución de este emperador.

La constitución del año 529 no hace sino poner de manifiesto la constatación de JUSTINIANO de que ciertos bienes del emancipado no son objeto de la collatio descendentium en la sucesión paterna; esta regla es ya anterior a la constitución del año 529. En este sentido, se opone a la opinión de PRINGSHEIM ${ }^{136}$, que hace suya la doctrina expuesta por FEIN ${ }^{137}$ y según la cual el emperador LEON había dejado subsistir la distinción entre la dos profectitia y la adventitia, distinción que sólo habría sido suprimida de forma indirecta por JUSTINIANO en el año $529^{138}$. Esta opinión se fundaba en el principio según el cual, la hija emancipada estaba obligada a la collatio dotis en virtud del Edicto del Pretor relativo a la collatio bonorum ${ }^{139}$. Habiendo dispensado JUSTINIANO a la hija emancipada de la collatio dotis adventitiae, el mismo régimen se habría aplicado a la hija in potestate ${ }^{140}$.

\section{MEDIDAS PROCESALES}

En este apartado analizaremos las técnicas y medios de carácter procesal que posibilitan el desarrollo de la colación de la dote. Sus mecanismos jurisdiccionales sufren cambios en sus estructuras por el transcurso del tiempo. Bajo esta perspectiva, se pueden distinguir diversos periodos:

\subsection{Desde la introducción retórica de la colación hasta Antonio Pío}

La posición en la que se puede encontrar la mujer en su matrimonio, en el momento de la muerte de su paterfamilias, determina la forma de cumplir con la colación:

135 C. VI,20,20,3.

136 PRINGSHEIM. Op. cit. p. 540 y ss.

137 FEIN. Op. cit. p. 192.

138 C. VI,6,61,6.

139 Cf. SLEZGHTER, art. cit. nota 96, p. 193.

140 PRINGSHEIM. Die Collatio dotis an die emanzipati, S.D.H.I,4, 1958, p. 542. 


\subsubsection{Colación de la dote durante el matrimonio}

La mujer puede estar unida en justo matrimonio en el momento que fallece su ascendiente. Esta situación implica que ella no pueda entregar directamente los bienes dotales a sus hermanos, porque están en poder de su marido. Este patrimonio cumple una finalidad civil, «ad sustineda onera matrimonii». Por este motivo el magistrado obliga a la hija a que preste garantías suficientes que aseguren la colación, cautio de conferenda dote.

\section{ULPIANO afirma:}

«Si sub conditione pater,vel extraneus dotem promiserit, cautione opus erit, ut tunc conferat mulier dotem, quum dotata esse coeperit» ${ }^{141}$.

Esta cautio es idéntica a la que deben prestar los emancipados como medida afianzadora de que aportarán sus bienes. ULPIANO así lo señala:

$$
\text { «..Iubet autem praetor ita fieri collationem, ut recte caveatur» }{ }^{142} \text {. }
$$

La prestación de esta promesa formal antecedente, por parte de la mujer, conlleva el sometimiento de todos los coherederos al fuero de una tercera persona que adquiere funciones arbitrales de los intereses en conflicto.

PAPINIANO confirma esta tesis para el caso de retraso injustificado de la colación de una dote por parte de su beneficiaria:

«...viri boni arbitratu cogetur.. dotis conferre, quum emancipatus frater ... conferat...» ${ }^{143}$.

Este jurista confirma nuestras sospechas de que el pretor se sirve de los recursos procesales por él creados, con o sin ayuda de la jurisprudencia, para aplicarlos a ambas clases de colaciones.

La mujer tiene facultad para reforzar esta garantía con sponsores, que actuan como fiadores de la obligación contraída.

POMPONIO nos informa de que las estipulaciones realizadas por los emancipados con sus coherederos alieni iuris eran aseguradas del mismo modo:

«... Et reis, et pignoribus recte caveri de collatione, et ita ego quoque puto» ${ }^{144}$.

141 D. $37,7,1,7$.

142 ULPIANO. Reg. 28,4.

143 D. $37,6,5,1$.

144 D. $37,6,1,9$. 
Los juristas señalan la posibilidad de que otros sujetos puedan realizar funciones de administración sobre el patrimonio de los emancipados. ULPIANO manifiesta:

«Si frater cavere non possit, curator portionis eius constituitur, apud quem refecta pecunia collocetur, ut tunc demum recipiat, quod redactum est, quum bona propia contulerit» ${ }^{145}$.

No se puede dudar ya que los instrumentos jurídicos pretorios vigentes para la collatio bonorum son por analogía aplicables a la collatio dotis. Sin embargo las situaciones, en las que se puede encontrar la esposa respecto a sus nupcias, condicionan de modo absoluto las vías del procedimiento que puede utilizar la mujer.

ULPIANO señala que:

"Quamvis autem Edictum Praetoris de cautione loquatur, tamen etiam re posse fieri collationem, Pomponius libro septuagesimo nono ad Edictum scripsit; aut enim re, inquit, aut cautione facienda collatio est. Igitur dividat, inquit, bona sua cum fratribus, et quamvis non caveat, satisfacit Edicto» ${ }^{146}$.

El jurista afirma que el emancipado puede hacer la collatio o mediante la caución o a través de la entrega directa de los bienes. Ambos sistemas son puestos en una situación de igualdad, «... aut enim re, inquit, aut cautione» y así el sui iuris decide libremente si quiere una vía u otra. Si no tiene bienes optará por la cautio para que posteriomente en el acto de división de la herencia, el juez detraiga, de su parte proporcional hereditaria, la cuantía que distribuirá a prorrata entre sus hermanos heredes sui. Sin embargo, la mujer dotada no tiene esta posibilidad de libre elección. La hija puede tener un gran patrimonio en concepto de dote, pero constante matrimonio, no puede re conferre porque aquella está en poder del marido, cumpliendo un destino jurídico-económico-social del que no se puede desligar. La entrega directa de los bienes por parte de la mujer no es posible porque está casada. Este hecho produce una situación de inseguridad para sus hermanos que debe ser garantizada por otros medios.

ULPIANO en relación con la obligación de colacionar a la que están sujetos los emancipados señala que deben prestar caución como medida previa que garantiza su cumplimiento:

145 D. $37,6,1,10$.

146 D. $37,6,1,11$. 
«Si igitur constet inter partes, quid sit in bonis emancipati, sufficiens collatio est divisio: si non constet..., sed dicantur quaedam non esse in commune redacta, tunc propter incertum cautio erit interponend ${ }^{147}$.

Del mismo modo, la mujer responde ante sus hermanos con una fianza preventiva que cubre su patrimonio dotal.

Por otro lado, en ciertas ocasiones, es posible que el marido haya dilapidado todos los bienes de un modo fraudulento. En este supuesto la hija tiene la posibilidad de remitir sus deudas con sus hermanos, a costa de la cuota hereditaria que le corresponde, de su ascendiente fallecido.

El emperador GORDIANO, recogiendo una tradicional práctica jurisprudencial para la collatio bonorum, extiende la posibilidad para la mujer dotada de deducir del caudal relicto la cuota proporcional que debía colacionar:

«Dotis quidem petitio perseverante matrimonio tibi non competebat; quamvis enim eam, intestato patre defuncto, fratri conferre debueras, non tamen eo nomine adversus maritum tibi actio potuit esse, quum eo minus in partem tibi delatae successionis patris auferre potueris» ${ }^{148}$.

En conclusión, la hija que, constante matrimonio, debe colacionar su dote tiene estas posibilidades:

- Prestar una cautio de conferenda dote, que puede ser reforzada con la presencia de terceros, marido, parientes, acreedores, familiares, etc., que actúan como sponsores del vínculo jurídico creado entre la mujer y los coherederos. Una vez disuelto el matrimonio puede hacerla efectiva por lo estipulado, con la entrega de los bienes que haya recuperado.

- Prestar y cumplir la garantía reduciendo sus derechos civiles de la cuota hereditaria que la hubiese correspondido.

\subsubsection{Colación de la dote disuelto el matrimonio}

Otra situación bien diferente se produce cuando el matrimonio está disuelto por causa de divorcio o de fallecimiento del marido. El ordenamiento civil clásico concede a la mujer el derecho legítimo a la restitución de su dote.

ULPIANO confirma este ius distrahendi del que goza la esposa:

«Soluto matrimonio solvi mulieri dos debet, nec cogitur maritus alii eam ab initio stipulanti promittere, nisi hoc ei nihil nocet;nam si

147 D. 37,6,1,11.

148 C. $V I, 20,5$. 
incommodum aliquod maritus suspectum habet, non debere eum cogii alii, quam uxori promittere, dicendum ¿st; haec, si sui iuris mulier est $\gg^{149}$.

Si éstas son las circunstancias familiares de la hija, en el momento en que fallece su ascendiente paterno, tiene otras vías para cumplir con el régimen collationis:

a) Si está dispuesta a recuperar sus bienes, pero no ha ejercido ningún tipo de acción procesal, colaciona ésta a sus hermanos coherederos para que actúen frente al marido. No tiene importancia alguna que la dote sea profecticia o adventicia, porque se restituye al tercero, según lo que hayan pactado las partes que llevaron a cabo la estipulación. Si no se hubiese acordado nada, la restitución se hace siempre en favor de la mujer, porque aunque hubiese permanecido bajo la patria potestad, ha fallecido la persona que la ejercía ${ }^{150}$.

El objeto collationis que se cede por la mujer es la ACTIO REI UXORIAE, calificada por CICERON como actio in bonum et aequum concepta. El juez fija la condena conforme a criterios de equidad valorando las circunstancias del caso en concreto que ha estado en litispendencia ${ }^{151}$.

ULPIANO confirma que la mujer, que haya finalizado una estipulación de constitución de dote en su favor, está obligada a la carga de la colación:

«Si in stipulatum deducta sit dos, si quidem ipsa mulier stipulata sit, vel ipsi negotium gestum, aeque conferre cogetur; si vero alii quaesita est stipulatio, dicendum est, cessare collationem; et si tantum promissa sit dos, collatio eius fiet ${ }^{152}$.

El autor señala que basta una promissio dotis en favor de ella para que nazca la obligación de colacionar.

Este procedimiento es análogo al de la colación de los emancipados. Estos pueden aportar las acciones de las que son titulares, como acreedores, por créditos contraídos con terceras personas. PAULO indica este supuesto homólogo para la colación de la dote:

«Id quoque, quod sub conditione ex stipulatu debetur, emancipato conferri debet ${ }^{153}$.

149 D. $24,3,2$.

150 D. $23,4,7$. D. $24,3,2,1$. D. $24,3,3$.

151 CICERON. Top. 7,22. CICERON, De off, 3,15,61.

152 D. $37,7,1,1$.

153 D. $37,6,2,3$. 
La mujer entrega la acción a los coherederos para que la ejerciten frente a su marido. En ocasiones, ocurría que había dilapidado todos los bienes, fruto de una mala administración, en fraude de su matrimonio, de su esposa y de sus hijos.

La normativa clásica resuelve esta situación protegiendo los derechos de la mujer sobre el caudal relicto del de cuius. ULPIANO examinó este problema con gran interés y dio protección jurídica a las mujeres frente a la irresponsabilidad patrimonial de sus cónyuges. El autor señala que:

"Quodsi iam factum divortium est, et maritus non sit solvendo, non debebit integra dos computari mulieri, sed id, quod ad mulierem potest pervenire, hoc est, quod facere maritus potest ${ }^{154}$.

Pensamos que el texto no está interpolado. Muchas veces los compiladores expresan con sus palabras y con el estilo lingüístico propio de su época, normas que han recogido de los jurisconsultos clásicos, y a pesar de ello no hay ningún tipo de alteración de contenido sustancial. Esta idea viene avalada por los propios ministros bizantinos encabezados por TRIBONIANO que señalan que:

«Et novimus Ulpianum sapientissimum talia quaessisse, et inope viro comperto iuvisse mulierem, et in quantum vir idoneus est, collatione mei fieri voluisse» ${ }^{155}$.

La beneficiaria de la dote tiene la obligación de colacionarla en la medida en que puede serle restituida. Esto confirma que el juez, a la hora de fijar la condemnatio, tiene libre margen de actuación, pues debe valorar todas estas circunstancias, condemnatio incerta. La ley traslada el riesgo de la insolvencia de la mujer a sus hermanos coherederos.

b) Si la esposa ha recuperado sus bienes, los entrega directamente a sus hermanos, collatio re, como medio ordinario de cumplimiento, «aut enim re, inquit, aut cautione facienda collatio est» ${ }^{156}$.

\subsubsection{Colación de la dote y caución}

ULPIANO señala que el magistrado «ad collationem dotis cogat filiam si petat bonorum possessionem ${ }^{157}$. Pensamos que la hija debe prestar la garantía caucional a sus coherederos una vez que ha pedido el beneficio de la posesión de los bienes. El Pretor, previa causae cognitio, verifica si la mujer tiene el título

154 D. 37,7,1,6.

155 N. C. $16,6,1$.

156 D. $37,6,1,11$.

157 D. $37,7,1$. 
suficiente para ser poseedora de los bienes. Una vez practicado este examen prejudicial le obliga conexamente a la prestación de garantía, para posteriormente concederle la datio bonorum possessionis ${ }^{158}$.

No podemos aceptar la tesis de LENEL que señala que «... in Moment, wo der emancipatus die bonorum possessio, begehrt, noch gar nicht festzustehen braucht, ob und wer sie noch neben ihm begehert» ${ }^{159}$.

El pretor no puede conceder primero la posesión y después obligar a la mujer a prestar la promesa, porque ella recibe un beneficio que perjudica a sus hermanos, si luego no la lleva a cabo. No podemos olvidar, que la concesión de la bonorum possessio atribuye el título de heredero pretorio. La hija, al igual que el emancipado, no puede optar por la entrega directa de los bienes, o prestar la caución a su libre elección. Si su matrimonio está en vigor tiene que prestar obligatoriamente la caución porque la dote está destinada indisolublemente a su matrimonio. LENEL indica que el magistrado obliga a la hija a colacionar su dote. Si está cumpliendo la misión que el ordenamiento prescribe, esto es servir de pilar económico a la vida del matrimonio, no nos queda otra alternativa que pensar que el magistrado obliga a la mujer a prestar la caución, como condición sine qua non, para participar en la herencia paterna. Si no la lleva a cabo el iusdicente, de oficio, le deniega la posesión de los bienes. La mujer puede apoyarse subsidiariamente en el patrimonio de terceras personas. Si no aprovecha todas las oportunidades que el Edicto la brinda es porque actúa con temeridad y mala fe, ante la invitación honoraria de cumplir. Si está interesada, en verdad, en recibir una parte del as hereditario debe atenerse a las directivas que se le indican. Los recursos procesales previstos por el magistrado garantizan a todos los coherederos una seguridad jurídica sobre la cuota que van a recibir frente a intromisiones ilegítimas.

En este sentido estamos de acuerdo con la opinión de SZLECHTER que manifiesta que «... La collatio dotis ne pouvait intervenir qu'en faveur des héritiers, c'est-à-dire de ceux qui avaient obtenu la Bonorum Possessio; elle était due par la fille doteé, qui, elle aussi, avait acquis la qualité d'héritière» ${ }^{160}$.

El magistrado incoa un procedimiento único para todos los que piden la bonorum possessio. Una vez analizados todos los presupuestos y exigidas todas las garantías, concede la posesión a todos a la vez. Si esto no es así, el magistrado concedería el «título de heredero» sin ninguna garantía. Esto va contra el princi-

158 D. 37,7,1,1, ULPIANO. Libro XL ad Edictum. GUARINO. Op. cit. p. 70 dice que «Ma in diritto classico, la qualitá di erede, sepur pretorio, non scaturiva punto dalla promessa dell'editto, ne la adgnitio era accettazione, bensí il possesso dei beni ereditarii acquistavasi soltanto in base alla datio del pretore. Non avendo sino a aquel momento l'emancipato e il suus ancora assodato alcun diritto alla possessio dei beni del fondo, dovevasi ben dal Pretore eseguire un completa indagine al loro proposito le cui risultanze si sarebbero evinte dal decretum che ogni caso sarebbe stato emesso».

159 LENEL. Op. cit. \$ 25 (p. 144)

160 SZLECHTER $O p$. cit. p. 195. 
pio de seguridad jurídica que preside todas sus actuaciones. El sistema recogido por el Edicto es el de órdenes y grados. El magistrado concede un tiempo para las peticiones. Si no las hubiese se llama al grado siguiente ${ }^{161}$. Si éste es el mecanismo jurídico, nunca otorgará esta concesión en beneficio de unos sin haber resuelto la petición de los otros. Por este motivo, SZLECHTER afirma que «... La fille dotée devait alors rapporter la dot si elle voulait effectivement participer, avec ses cohéritiers, au partage des biens successoraux. Si elle ne conférait pas la dot, les héritiers pouvaiet lui refuser sa part successorale» ${ }^{162}$.

Los hermanos exigen la prestación de garantías de acuerdo con el magistrado. Si no las presta, no le concede el título de heredera pretoria, pues él es la única persona competente que puede legitimar para participar en la sucesión ab intestato paterna ${ }^{163}$. En esta línea, SZLECHTER se contradice porque señala que «En effet, le magistrat accordait, en principe, la Bonorum Possessio» sans examen, mais sous réserve que la demande correspondit aux conditions préveus par l'edit relatif a la Bonorum Possessio» ${ }^{164}$. No parece razonable que el pretor conceda esta posesión y después haga la indagación previa.

Lo más sencillo y lógico es pensar que el magistrado fiscaliza primero los presupuestos que recoge en su álbum, examen previo, para conceder a posteriori la posesión de los bienes ${ }^{165}$.

Existe además otra razón seria para pensar que los dos autores anteriores no tienen razón. En la época postclásica es cuando la petición de la bonorum possessio de los sucesores intestados equivale a su concesión. Así señala CONSTANCIO ad Populum la nueva presunción legal:

«Ut verborum inanium excludimus captiones, ita hoc observari decernimus, ut apud quemlibet iudicem vel etiam apud duumviros qualiscunque testatio amplectendae hereditatis ostendatur, statutis prisco iure temporibus coarctanda, eo addito, ut, etiamsi intra alienam vicem, id est prioris gradus properantius exseratur, nihilominus tamen efficaciam parem, quasi suis sit usa curriculis, consequatur» ${ }^{166}$.

No se puede dudar que la constitución se refiera a la sucesión pretoria, porque se hace alusión al plazo que los pretores establecieron en su Edicto, para la delación de la herencia y se trata también de la sucesión en grados.

161 ULPIANO. Reg. XXVIII, 10 señala que «Bonorum possessio datur parentibus et liberis intra anmum, ex quo petere potuerunt ceteris intra centum dies». ULPANO, Reg. XXVIII, 11 , añade que "Qui omnes intra id tempus si non petierint bonorum possessionem, sequens gradus admittitur, perinde atque si superiores non essent: idque per septem gradus fit».

162 SZLECHTER. Art. cit. p. 184 y ss.

163 GAYO. III XXIV.

164 SZLECHTER. Art. cit, p. 28 y ss.

165 GUARINO. Art. cit., p. 158.

166 C. VI,9,9. 
En conclusión, si la mujer no presta garantías suficientes, no consigue la bonorum possessio. PAULO así nos lo confirma:

«Si duo emancipati bonorum possessionem petierint, et unus contulerit, alter non contulerit, huius portio tantum ei, qui in potestate est, prodesse debet, non etiam emancipato, quoniam eius causa, qui in potestate est, denegantur ei actiones» ${ }^{167}$.

\subsection{Desde el rescripto de Antonino Pío al Bajo Imperio}

Cuando el emperador ANTONINO PIO completa las normas previstas en el álbum a través de su poder legislativo, abre nuevos caminos jurisdiccionales. $\mathrm{La}$ norma imperial desliga la collatio dotis de la sola intervención de los pretores. $\mathrm{Si}$ la hija es heredera civil y no pide la posesión de los bienes, puede participar en la sucesión $a b$ intestato civil del padre fallecido. En este supuesto, los hermanos coherederos piden al juez divisor de la herencia, que obligue a su hermana a colacionar la dote, como condición para que reciba las cuotas que él asigne. Las actuaciones se consiguen con la actio familiae erciscundae. Esta acción es de carácter civil y real. Todos los sujetos tienen la posición de demandantes y demandados. Consta de unas cláusulas especiales, la adiudicatio, y condemnatio incerta y es constitutiva de derechos de dominio. GAYO nos enseña:

«Titius iudex esto. Quod Lucii heredes de familia erciscunda ... iudicem sibi dari postulaverunt, quantum adiudicari oportet, iudex, adiudicato, quidquid ob eam rem alterum alteri praestare oportet ex fide bona, eius, iudex, alterum alteri condemnato, si non paret absolvito» ${ }^{168}$.

La legislación imperial concede al juez la facultad de que imponga a la hija los medios coercitivos necesarios para que cumpla con su cometido. Los mecanismos son exactamente iguales:

- Si el matrimonio no está en vigor, colaciona directamente la dote, o la acción de restitución a sus coherederos, pero si el matrimonio existe, el iudex conmina a aquélla a que preste una garantía patrimonial. Si ello no fuese posible, el árbitro detrae de su cuota la parte proporcional que debe colacionar a prorrata

167 D. $37,6,2,8$.

168 GAYO, III, 42 dice que «Adiudicatio est ea pars formulae qua permittittur iudici rem alicui ex litigatoribus adiudicare, velut si inter coheredis familiae erciscundae agatur, aut inter socios communi dividundo, aut inter vicinos finium regundorum; nam illic ita est: QUANTUM ADIUDICARI OPORTET, IUDEX TITIO ADIUDICATO». 
con sus hermanos ${ }^{169}$. El pretor pierde así la exclusividad sobre la colación de la dote en favor del juez divisor de la herencia. El Pretor, si la mujer se niega dolosamente a cumplir con la caución, la deniega la posesión de los bienes. El juez actúa de la misma forma, «... ad collationem dotis per arbitrum familiae erciscundae posse compelli». Si la mujer no sigue este camino es excluida:

Los emperadores DIOCLECIANO Y MAXIMO se dirigen a FILANTEA con «Dat. XI. Kal. Febre. Sirmii, Caess. Conss, <294>» en los siguientes términos:

«Filiae, licet maneat in sacris, si dotem non conferat, quam mortis tempore communis patris habuit, fratribus in eadem familia constitutis, actiones hereditarias denegari non ambigitur. Unde consulte ac pro iuris ratione collationem fratribus tuis, quos in patris communis mortis tempore fuisse potestate proponis, offeres ${ }^{170}$.

La mujer puede haber engañado a sus hermanos en el acto de la división de la herencia. El árbitro, o el Praeses Provinciae, examinadas las alegaciones de las partes, ordenarán que se restituya lo que, hecha la cuenta, hubieren visto que hay demás en poder de ella ${ }^{171}$.

Frente a la idea de los autores que piensan que la acción de división de la herencia es coercitiva, en el sentido de que los hermanos obligan con ella a la hermana a cumplir con la colación, pienso que es cierto, siempre que ésta decida participar en el concurso hereditario. Si esto no es así, este principio quiebra irremediablemente. TRIFONINO confirma esta tesis:

«Fuit quaestionis, an si, sua heres filia patri cum fratribus, contenta dote abstineat se bonis, compellatur eam conferre. Et hoc Divus narcus rescripsit, non compelli abstinentem se ab hereditate patris; ergo non tantum data apud maritum remanebit, sed et promissa exigetur etiam a fratribus; et est aeris alieni loco abscessit enim a bonis patris» ${ }^{172}$.

169 C. $6,20,5$, GORDIANO a ALEXANDRIAE, «Dotis quidem petitio perseverante matrimonio tibi non competebat; quamvis enin eam, intestato patre defuncto, frati conferre debueras, non tamen eo nomine adversus maritum tibi actio potuit esse, quum eo minus in partem tibi delatae successionis patris auferre potueris».

170 C. $6,20,12$.

171 C. 6,20,8, DIOCLETIANUS ET MAXIMIANUS, «Si soror tua in paternorum bonorum divisione te fefellit, nec dotem, quam acceperat a patre vestro intestato diem functo, contulit, praeses provinciae, examinatis partium allegationibus, cum bonis dotem confundi iubebit, et quod deducta ratione plus apud eam esse animadverterit, tibi restitui iubebit. Idem est, et si arbitrio dato divisio celebrata est».

172 D. 37,7,9. 
El emperador MARCO AURELIO dictamina por rescripto que la hija que utiliza el ius abstinendi está exenta de la obligación de colacionar. PAPINIANO confirma esta norma clásica pues señala que:

«Pater nubenti filiae quasdam res praeter dotem dedit, eamque in familia retinuit, ac fratribus sub conditione, si dotem et cetera, quae nubenti tradidit, contulisset, coheredem adscripsit; quum filiam se bonis abstinuisset, fratribus res non in dotem datas vindicantibus exceptionem doli placuit obstare, quoniam pater filiam alterutrum habere voluit» ${ }^{173}$.

\subsection{Cálculo}

Una vez examinados los medios que posibilitan la realización práctica de la collatio, debemos analizar cuáles son las reglas de cálculo que fijan el montante patrimonial que debe ser colacionado. La operación matemática es similar a la practicada por los emancipados, pero no idéntica. Si éstos detraen de su patrimonio activo todos los débitos, gastos y obligaciones a las que están obligados como sujetos pasivos, en favor de terceras personas, la mujer detrae de sus bienes y derechos, los gastos necesarios.

ULPIANO confirma esta norma aritmética:

"Quum dos confertur, impensarum necessariarum fit detractio, ceterarum non» ${ }^{174}$.

Debemos precisar lo que el ordenamiento cásico entiende por gasto necesario para saber qué es lo que realmente puede deducir la beneficiaria de la dote. ULPIANO da una definición de él:

«Necessariae hae dicuntur, quae habent in se necessitatem impendendi; ceterum si nulla fuit necessitas, alio iure habentur» ${ }^{175}$.

Esta idea no es objetiva, porque la apreciación de la necesidad de invertir un dinero o no, es subjetiva. Lo que para unas personas pueda ser necesario para otras puede resultar suntuoso o superfluo. Por este motivo, en caso de duda, es el juez el encargado de fijarlos, verificando además si han sido realizados en provecho de la mujer y de sus hijos.

PAULO nos confirma esta idea:

173 D. $37,7,8$.

174 D. $37,7,1,5$.

175 D. $25,1,1,1$. 
«Et in totum id videtur necessariis impensis contineri, quod si a marito omissum sit, iudex tanti eum damnabit, quanti mulieris interfuerit, eas impensas fieri. Sed hoc differt, quod factarum ratio habetur, etsi res male gesta est, non factarum ita, si ob id res male gesta est. Itaque si fulserit insulam ruentem, eaque exusta sit, impensas consequitur, si non fecerit, deusta ea nihil praestabit ${ }^{176}$.

Los jurisprudentes precisan con casos prácticos cuáles son estos gastos necesarios:

a) Obras necesarias realizadas en un horno, o en un almacén, así como los generados para ganar terreno al mar, o a un río ${ }^{177}$.

b) Los gastos generados por las reparaciones de edificios que amenazan ruina, y se arreglan en beneficio de la mujer, así como las mejoras en las fincas, un olivar, vides, etc. ${ }^{178}$

c) Los causados para atender a las diversas enfermedades de los esclavos de la esposa $^{179}$.

Para calcular los gastos, se tiene en cuenta el valor de los que se hayan efectuado, para comprobar si el conjunto patrimonial dotal ha sufrido un incremento o una disminución. ULPIANO nos dice que POMPONIO estaba de acuerdo con este sistema:

«Quod dicitur, necessarias impensas dotem minuere, sic erit accipiendum, ut et Pomponius ait,non ut ipsae res corporaliter deminuantur, utputa fundus vel quodcunque aliud corpus; etenim absurdum est, deminutionem corporis fieri propter pecuniam. Ceterum haec res faciet, desinere esse fundum dotalem, vel partem eius; manebit igitur maritus in rerum detentatione, donec ei satisfiat, non enim ipso iure corporum, sed dotis fit deminutio. Ubi ergo admittimus, deminutionem dotis ipso iure fieri? Ubi non sunt corpora, sed pecunia; nam in pecunia ratio admittit, deminutionem fieri. Proinde si aestimata corpora in dotem data sint, ipso iure dos deminuetur per impensas necessarias. Hoc de his impensis dictum est, quae in dotem ipsam factae sint; ceterum si extrinsecus, non imminuent dotem» ${ }^{180}$.

176 D. $25,1,3$.

177 D. 25,1,1,3, ULPIANO, Libro XXXVI ad Sabinum señala que "Inter neccessarias impensas esse Labeo ait, moles in mare vel flumen proiectas; sed et si pistrinum vel horreum necessario factum sit, in necessariiis impensis habendum ait. Proinde Fulcinius inquit, si aedificium ruens, quod habere mulieri utile erat, refecerit, aut si oliveta reiecta restauraverit, vel ex stipulatione damni infecti ne committatur, praestiterit».

178 D. $25,1,1,3$.

179 D. $25,1,2$. PAULO «vel in valetudinem servorum impenderit».

180 D. $25,1,5$. 
Este jurista indica que si la mujer desea recuperar su dote, pero no paga las impensas necesarias realizadas por su marido, éste tiene el ius retentionis sobre el conjunto patrimonial.

Bajo este marco jurídico, la mujer tiene que pagar los gastos necesarios a su marido porque es condición legal para que se le devuelva la dote. Si no cumple, la acción que se le concede al marido paraliza el conferimiento a la que está obligada la mujer con sus coherederos.

El derecho prevee sanciones para el retraso injustificado de la esposa de llevar su dote a colación. Si ella no atiende a la interpelación que le hacen sus hermanos, si no cede, o tarda en promover la acción de restitución, o en último término, se niega a consignar las cantidades recibidas, responde de su conducta jurídica reprobable:

PAPINIANO fija la sanción que sufre aquella:

«Filia, quae soluto matrimonio dotem conferre debuit, moram collationi fecit; viri boni arbitratu cogetur usuras quoque dotis conferre, quum emancipatus frater enim fructus conferat, et filia partis suae fructus percipiat $^{181}$.

Los autores clásicos dicen que los frutos de la dote pertenecen al marido, porque según la equidad soporta las cargas del matrimonio ${ }^{182}$. El castigo que señala el jurisprudente se produce en el momento que la mujer ha recuperado su dote y no la aporta a la masa hereditaria, para su división a título de colación, mora de conferendis collationis.

La hija debe entregar todas las accesiones, frutos e intereses, que haya generado la dote que está en su poder ${ }^{183}$.

\section{CONCLUSIONES}

8.1. La colación de la dote es un instituto que ha introducido el Pretor en su Edicto en el s. I a. C.

8.2. La collatio dotis apareció en el Edicto del Pretor a continuación de la collatio bonorum, con un titulo separado y aparte.

8.3. La jurisprudencia clásica no es la que da vida a la collatio dotis. Su intervención es decisiva en los Consejos Imperiales, a partir de ANTONINO PÍO, y sus decisiones influirán en toda la normativa imperial sobre la colación de la dote posterior.

181 D. $37,7,5,1$.

182 D. 23,3,7, ULPIANO, Libro XXXI ad Sabinum señala que «Dotis fructum ad maritum pertinere debere aequitas suggerit; quum enim ipse onera matrimonii subeat, aequum est, eum etiam fructus percipere». D. 23,3,7,1, ULPIANO, Libro XXXI ad Edictum.

183 D. $37,7,5,1$. 
8.4. La collatio dotis tiene un fundamento análogo, pero, no idéntico, al de la collatio bonorum. En aquélla la entrega de la dos constituye un anticipo patrimonial en vida, que disminuye los derechos hereditarios civiles de los otros sucesores ab intestato y con ésta se corrigen las distorsiones patrimoniales generadas por la patria potestad.

8.5. El Edicto pretorio obligaba a la hija que pedía la bonorum possessio, estuviera emancipada o in potestate, a la colación de la dote.

8.6. La hija instituida heredera no estaba obligada a la collatio dotis, cuando, después de la petición de uno de sus hermanos, ella había aceptado la bonorum possessio contra tabulas. Esta dispensa de colacionar por parte de la hija instituida heredera no era absoluta. La regla no se aplicaba, por ejemplo, cuando el padre imponía a su hija la collatio dotis como condición de su participación en la sucesión (D. 37,7,8), o cuando la parte hereditaria que la hija obtenía en la sucesión pretoria, era superior a la que concedía el testamento (D.37,7,3). En conclusión, la collatio dotis no se imponía a la hija dotada mas que en la medida en que era llamada a la sucesión paterna en virtud del mismo derecho que sus coherederos, de lo contrario, estaba dispensada.

8.7. El Pretor aplicó las técnicas jurídicas procesales de la collatio bonorum a la colación de la dote, pero cada una de ellas tiene su propia identidad e independencia.

8.8. El emperador ANTONINO PIO extiende la obligación de colacionar a la hija heredera civil. Posteriormente, GORDIANO concede el beneficio de la colación a los emancipados.

8.9. No compartimos las teorías de ALBERTARIO y de PRINGSHEIM. El emperador GORDIANO, por un régimen de reciprocidad, extendió la carga de la colación a la hija, porque los hermanos emancipados colacionaban sus bienes con ésta. De este modo nace el principio de que los sucesores colacionan cuanto procede del ascendiente común a quien se sucede. Consecuencia de ello es el origen de los principios que posteriormente propiciarán la creación de la collatio descendentium.

8.10. Creemos que, en época clásica, la hija colacionaba tanto la dos adventitia como la dos profectitia.

8.11. En relación con los medios de garantía que presta la mujer para cumplir con la colación, distinguimos dos situaciones:

a) Si fallece el ascendiente, y el matrimonio permanece, tiene que prestar caución obligatoriamente, porque la dote está destinada a sostener las cargas del matrimonio, o puede sustituir su valor con la entrega directa de los bienes, o a través de fianza o reducción de su porción en la cuota hereditaria en la medida en la que deba colacionar.

b) Si el matrimonio no subsiste, la mujer ejercita o cede las acciones de restitución. Si el marido ha derrochado todo el conjunto patrimonial, es suficiente garantía la cesión de la retribución. 